\title{
Nanomedicine-Based Therapeutics to Combat Acute Lung Injury
}

This article was published in the following Dove Press journal:

International Journal of Nanomedicine

\author{
Shuai Bian (D) \\ Hongfei Cai ${ }^{1}$ \\ Youbin Cui ${ }^{1} *$ \\ Wanguo Liu $^{2}$,* \\ Chunsheng Xiao $\mathbb{D D}^{3}$ \\ 'Department of Thoracic Surgery, The \\ First Hospital of Jilin University, \\ Changchun, I3002I, People's Republic of \\ China; ${ }^{2}$ Department of Orthopedic \\ Surgery, China-Japan Union Hospital of \\ Jilin University, Changchun, I30033, \\ People's Republic of China; ${ }^{3}$ Key \\ Laboratory of Polymer Ecomaterials, \\ Changchun Institute of Applied \\ Chemistry, Chinese Academy of Sciences, \\ Changchun, 130022, People's Republic of \\ China
}

*These authors contributed equally to this work

Correspondence: Youbin Cui

Department of Thoracic Surgery, The

First Hospital of Jilin University,

Changchun, I3002I, People's Republic of

China

Email cuiyb@jlu.edu.cn

Wanguo Liu

Department of Orthopedic Surgery,

China-Japan Union Hospital of Jilin

University, Changchun, I 30033, People's

Republic of China

Email liuwanguo6016@jlu.edu.cn

\begin{abstract}
Acute lung injury (ALI) or its aggravated stage acute respiratory distress syndrome (ARDS) may lead to a life-threatening form of respiratory failure, resulting in high mortality of up to $30-40 \%$ in most studies. Although there have been decades of research since ALI was first described in 1967, the clinical therapeutic alternatives for ALI are still in a state of limited availability. Supportive treatment and mechanical ventilation still have priority. Despite some preclinical studies demonstrating the benefit of pharmacological interventions, none of these has been proved completely effective to date. Recent advances in nanotechnology may shed new light on the pharmacotherapy of ALI. Nanomedicine possesses targeting and synergistic therapeutic capability, thus boosting pharmaceutical efficacy and mitigating the side effects. Currently, a variety of nanomedicine with diverse frameworks and functional groups have been elaborately developed, in accordance with their lung targeting ability and the pathophysiology of ALI. The in-depth review of the current literature reveals that liposomes, polymers, inorganic materials, cell membranes, platelets, and other nanomedicine approaches have conferred attractive therapeutic benefits for ALI treatment. In this review, we explore the recent progress in the study of the nanomedicinebased therapy of ALI, presenting various nanomedical approaches, drug choices, therapeutic strategies, and outcomes, thereby providing insight into the trends.
\end{abstract}

Keywords: acute lung injury, acute respiratory distress syndrome, drug delivery, nanoparticle, nanomedicine

\section{Introduction}

Acute lung injury (ALI) or its aggravated stage acute respiratory distress syndrome (ARDS) is a common cause of respiratory failure in severely ill patients. Despite substantial progress in intensive care therapy and organ supportive technology, the mortality of ALI remains high at 30\%-40\% in most studies. ${ }^{1,2}$ The most common cause of ALI is a bacterial or viral infection. For example, patients who are infected with SARS-CoV-2 can present with pneumonia and hypoxemia, even progressing to ALI/ ARDS. ${ }^{3}$ Sepsis, aspiration of chemical agents and gastric contents, and shock are other common causes of ALI. ${ }^{4}$ The pathogenesis and pathophysiology of ALI are characterized by the destruction of alveolar-capillary integrity and by increased permeability, resulting in fluid, proteins, inflammatory agents and red blood cells accumulating in the alveolar space, ${ }^{2}$ and the clearance ability of the lung also being impaired. ${ }^{5}$ Clinical treatment of ALI/ARDS focuses on early diagnosis, control of infections, supportive ventilation, careful fluid management, and general supportive measures. ${ }^{2}$

Until now, clinical short-term or long-term mortality has not been able to be reduced by pharmaceutical drugs, ${ }^{6}$ but some pharmacologic agents have been 
proved to be effective in ameliorating ALI/ARDS. Glucocorticoids, such as dexamethasone, when administrated at an early stage, may decrease the duration of supportive ventilation, as well as the overall mortality, ${ }^{7}$ but they are harmful at approximately 2 weeks after ARDS has been diagnosed. ${ }^{8}$ Neutrophil elastase increases the permeability of the alveolar-capillary barrier and causes proteolytic lung tissue damage. ${ }^{2}$ Neutrophil elastase inhibitors, such as sivelestat, could be optional for the treatment of ALI; however, a multi-national clinical trial proved that sivelestat therapy was unsuccessful. ${ }^{9}$ Simvastatin has been reported to prevent organ dysfunction experimentally in ALI by decreasing vascular inflammation and leakage. ${ }^{10}$ However, a clinical trial reported that, although its safety was guaranteed and its adverse effects were minimal, simvastatin did not show distinct clinical benefits. ${ }^{11}$ Inhaled nitric oxide can improve oxygenation and lung function but may have side effects or even be harmful when applied improperly. ${ }^{12}$ Gene silencing, via short-interfering RNA (siRNA) to protect the integrity of the epithelial-endothelial barrier and prevent lung cell death, is a promising therapeutic option, but its application has been hampered by delivery technology challenges and safeties. ${ }^{13}$ Surfactant replacements, anticoagulation, and antioxidants have shown some effects in experiments but have failed in clinical trials ${ }^{14}$ (Table 1).

The limited success of pharmacological therapies forces us to develop new agents to combat ALI. The rapid development of nanomedicine might shed new light on this issue. Nanomedicines that possess active or passive targeting abilities have shown therapeutic advantages in various diseases. For example, it is recommended that nano-formulating dexamethasone be used to improve the efficacy in treating COVID-19, due to its ability to target hyper-activated immune cells, as well as its anti-edema activity. ${ }^{15}$ Therapeutic agents such as drugs, siRNA, and proteins can be conjugated or encapsulated inside nanomedicines. ${ }^{16,17}$ In the presence of ALI, there arose enhanced permeability of blood vessels, along with alterations in oxidants, $\mathrm{pH}$ and enzymes in the microenvironment, as well as regulation of the expression of various cell surface receptors. ${ }^{18}$ The above characteristics offer targets for site-specific delivery and the microenvironment for responsive drug release. To this end, the nanomedicine for ALI has broad alternative therapeutic strategies, including the delivery of anti-inflammatory agents to the disease site, ${ }^{19-34}$ the direct scavenging of inflammatory factors, ${ }^{35-47}$ the regulating of inflammatory cell activities, ${ }^{48-59}$ or the modulating of inflammatory signaling pathways. ${ }^{60-73}$ Various nanomedicines act on different cells or pathophysiology processes to achieve therapeutic effects, many of which have demonstrated satisfying in vitro and in vivo effects.

In this review, we will focus on a systematic overview of the state-of-the-art and advances in therapeutic nanomedicines for ALI. Firstly, a brief profile of essential cellular targets of nanomedicine for enhanced therapeutic effects will be presented. Subsequently, the diverse nanomedicines will be categorized into four groups and their applications in the treatment of ALI will be shown in elaborate detail. Lastly, we will analyze both the ongoing chances and challenges of nanomedicine-based therapy for ALI, especially presenting some of the innovative technologies that will navigate the future direction of nanomedicine, such as nanorobotics, machine learning and artificial intelligence (Figure 1).

\section{Cellular Targets for Nanomedicine}

During ALI, the damage of the alveolar-capillary barrier increases vascular permeability and fluid accumulation., ${ }^{2,4}$ This process is mediated by macrophages, neutrophils, and epithelial and endothelial cells through the innate immune response. $^{74}$

Alveolar macrophages (AMs) are resident cells in the alveoli that use a variety of mechanisms as a defense against the invasion of foreign particles and pathogens at the first line. ${ }^{75}$ Upon stimulation, resting macrophages (M0) are activated through classical and alternative pathways that are polarized and mainly classified into pro-inflammatory phenotype (M1) and anti-inflammatory phenotype (M2). ${ }^{76}$ The M1 macrophages can release various potent pro-inflammatory cytokines including IL-1 $\beta$, IL- 6 , and TNF- $\alpha .^{77}$ Modulation of AMs has been found to mitigate lung injury by attenuating neutrophil accumulation and reducing pro-inflammatory cytokines. $^{78}$ The mannosylated nanomedicine can target to macrophages by mannose receptors, ${ }^{25,52,61}$ and sialic acid bound to the E-selectin on the macrophages ${ }^{29,67}$ can also be utilized for active targeting. Because nanoparticles can be easily phagocytosed by macrophages, they possess a superior ability to control the inflammatory responses mediated by macrophages. ${ }^{37,45-47,62,64,67,68,71,73,79}$

Among the leukocytes at the sites of inflammation, neutrophils are the first to be recruited in response to chemotactic factors. ${ }^{80}$ They migrate across the endothelium and through the epithelium into the alveoli, then release histotoxic mediators to damage lung tissue, such as reactive oxygen species (ROS), neutrophil extracellular 
Table I The Medication to Construct Nanomedicine for ALI/ARDS

\begin{tabular}{|c|c|c|c|}
\hline Medication & Therapeutic Mechanisms & Drawbacks & Ref. \\
\hline \multicolumn{4}{|l|}{ Glucocorticoids } \\
\hline $\begin{array}{l}\text { Dexamethasone, } \\
\text { Methylprednisolone }\end{array}$ & $\begin{array}{l}\text { Inhibit production of inflammatory cytokines, } \\
\text { attenuate fluid accumulation and anti-fibrosis }\end{array}$ & $\begin{array}{l}\text { Various side effects including hypertension, Cushing's } \\
\text { syndrome, gastrointestinal bleeding, } \\
\text { immunosuppression, bone necrosis and osteoporosis } \\
\text { etc. }\end{array}$ & {$[15,136]$} \\
\hline \multicolumn{4}{|c|}{ Anti-inflammatory agents and antioxidants } \\
\hline Curcumin & $\begin{array}{l}\text { Reduces inflammation by inhibiting NF- } \mathrm{KB} \text { and } \\
\text { activating protein-I, by down-regulating COX-2 and } \\
\text { inducible nitric oxide synthase }\end{array}$ & $\begin{array}{l}\text { Poor water solubility and fast degradation result in } \\
\text { low bioavailability }\end{array}$ & {$[29,70]$} \\
\hline Resveratrol & $\begin{array}{l}\text { Anti-inflammation by targeting MAPK and NF- } \mathrm{kB} \text {, } \\
\text { anti-oxidation by increasing the activity of antioxidant } \\
\text { enzymes }\end{array}$ & $\begin{array}{l}\text { Low bioavailability and solubility, require to be } \\
\text { consumed regularly at a high dose }\end{array}$ & {$[|9,7|]$} \\
\hline$\alpha$-bisabolol & $\begin{array}{l}\text { Anti-inflammation and anti-oxidation, inhibits pro- } \\
\text { inflammatory cytokines }\end{array}$ & $\begin{array}{l}\text { Highly lipophilic and easily oxidizable, easily forming } \\
\text { two bisabolol oxides }\end{array}$ & {$[23,137]$} \\
\hline EUK-I34 & $\begin{array}{l}\text { A synthetic salen-manganese complexes, small } \\
\text { molecule SOD/catalase mimetic, scavenges ROS }\end{array}$ & Poor solubility and stability & {$[35, \mid 38]$} \\
\hline Oleic acid & $\begin{array}{l}\text { Inhibits upregulated superoxide anion and elastase in } \\
\text { activated neutrophils, reduces ROS }\end{array}$ & $\begin{array}{l}\text { Extremely high lipophilicity, infeasible to formulate } \\
\text { into injectable aqueous formulation }\end{array}$ & {$[48,139]$} \\
\hline \multicolumn{4}{|l|}{ Inhibitors } \\
\hline TPCA-I & $\begin{array}{l}\text { An IKB kinase-2 (IKK-2) inhibitor, blocks NF- } \mathrm{KB} \\
\text { nuclear translocation, reduces inflammatory cytokine } \\
\text { production }\end{array}$ & Insoluble in water, lack of tissue targeting feature & {$[28, \mid 40]$} \\
\hline Simvastatin & $\begin{array}{l}\text { 3-hydroxy-3-methylglutaryl coenzyme A (HMG- } \\
\text { CoA) reductase inhibitor, reduces vascular } \\
\text { inflammation and permeability, protects endothelium }\end{array}$ & $\begin{array}{l}\text { Require high-dose and prolonged treatment, which } \\
\text { increases the risk of liver toxicity and myopathy }\end{array}$ & {$[21,60,141]$} \\
\hline $\begin{array}{l}\text { Cilomilast, } \\
\text { Rolipram }\end{array}$ & $\begin{array}{l}\text { PDE4 inhibitors; repress neutrophil overactivation } \\
\text { through regulating intracellular levels of cAMP }\end{array}$ & $\begin{array}{l}\text { Emesis, nausea and headache caused by brain } \\
\text { penetration; low therapeutic index }\end{array}$ & {$[50,51]$} \\
\hline Sivelestat & $\begin{array}{l}\text { Second-generation NE inhibitor; inhibit NE activity } \\
\text { to preventing NETs formation }\end{array}$ & $\begin{array}{l}\text { Hypersensitivity, hepatobiliary disorders, anemia, } \\
\text { protein urine, protein total decreased; failed in } \\
\text { clinical trial }\end{array}$ & {$[49, \mid 42]$} \\
\hline Piceatannol & $\begin{array}{l}\text { Spleen tyrosine kinase inhibitor, blocks "outside-in" } \\
\beta 2 \text { integrin signaling in leukocytes, reduced } \\
\text { neutrophil adhesion and migration }\end{array}$ & $\begin{array}{l}\text { Poor solubility, poor bioavailability and biological } \\
\text { activity }\end{array}$ & {$[58,143]$} \\
\hline PP2 & $\begin{array}{l}\text { Src tyrosine kinase inhibitor, blocks the recruitment } \\
\text { and activation of various immune cells, reduces } \\
\text { vascular permeability and tissue inflammation }\end{array}$ & $\begin{array}{l}\text { Non-selective and inhibits many other kinases with } \\
\text { similar affinities }\end{array}$ & {$[34, \mid 44]$} \\
\hline Ruthenium red & $\begin{array}{l}\text { Transient receptor potential vanilloid } 4 \text { (TRPV4) } \\
\text { inhibitor, blocks force-sensitive TRPV4-mediated } \\
\text { calcium signaling to reduce vascular permeability }\end{array}$ & $\begin{array}{l}\text { Non-selective transient receptor potential (TRP) } \\
\text { inhibitor and interacts with a number of non-TRP } \\
\text { proteins }\end{array}$ & {$[30, \mid 45]$} \\
\hline
\end{tabular}




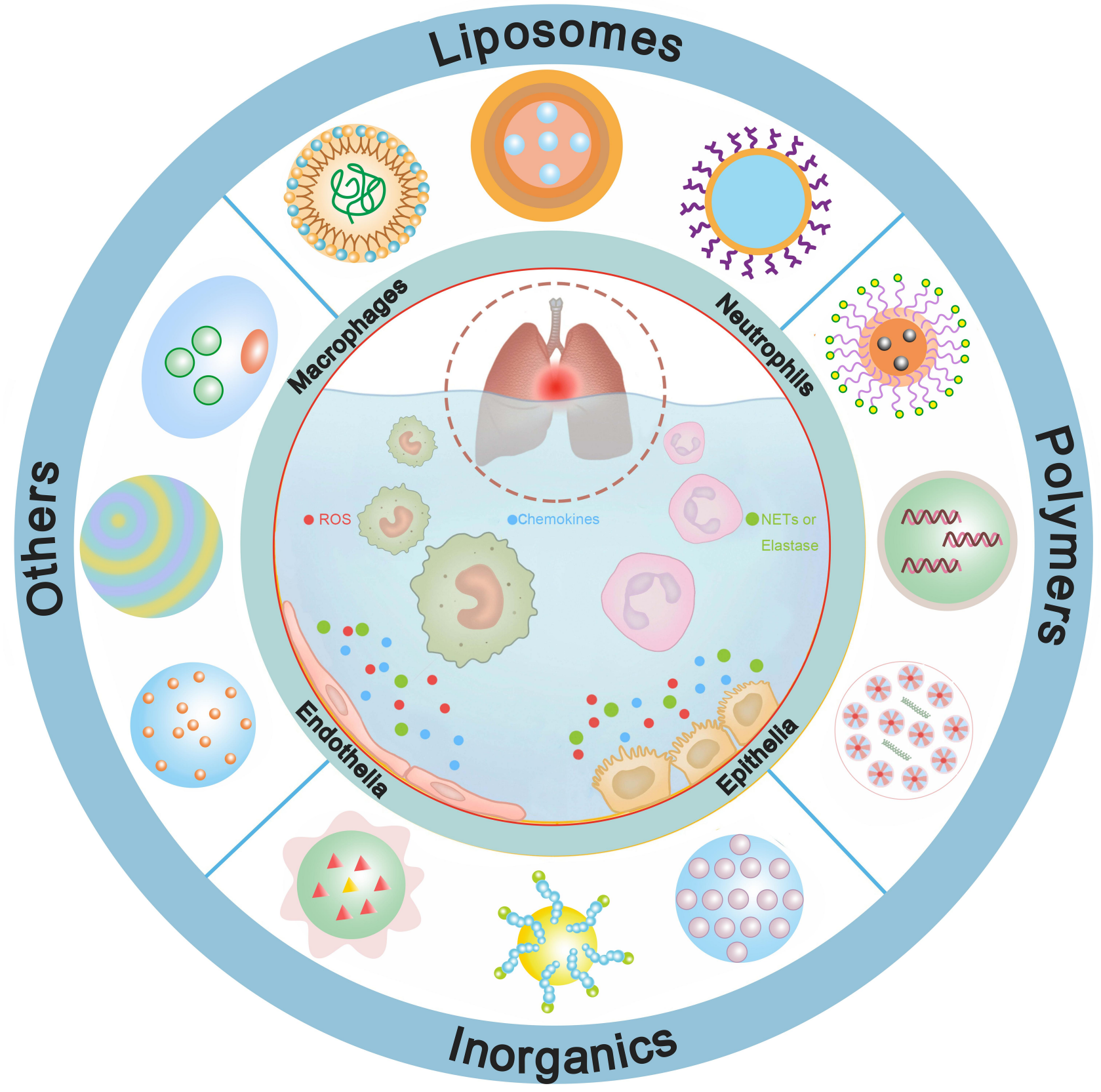

Figure I Nanomedicines can be fabricated based on various nanomaterials, including liposomes, polymers, inorganics, cell membranes, platelets, etc. They interfere one or more pathophysiologic processes of ALI to present beneficial effects.

traps (NETs), and proteases, ${ }^{81}$ as well as disrupting the endothelial-epithelial barrier. ${ }^{82}$ Nanomedicine can suppress neutrophil function by inhibiting upregulated superoxide anions and elastase, ${ }^{48,49}$ repressing activity of neutrophil overactivation by inhibiting phosphodiesterase 4 (PDE4) activity ${ }^{50,51}$ and detaching neutrophil adherence by blocking integrin signaling, ${ }^{58}$ or using neutrophils as vehicles ${ }^{54,56,57}$ for targeted ALI therapy.
Restoring the integrity of the endothelial-epithelial barrier is critical in ALI therapy. ${ }^{83,84}$ As the primary injured structure, the pulmonary epithelium is subject to dissociation of intercellular junctions ${ }^{85}$ and cell death, ${ }^{31}$ but is more resistant to injury than the endothelium. ${ }^{86}$ The endothelial junctions' breakdown or the endothelial cells' death will increase the lung's vascular permeability, thus resulting in excessive fluid and protein leakage into the 
alveoli. ${ }^{2}$ To target the endothelium and epithelium, intercellular adhesion molecule-1 (ICAM-1), ${ }^{87}$ plateletendothelial cell adhesion molecule (PECAM-1) ${ }^{88}$ and surfactant protein $(\mathrm{SP})^{89}$ can be bio-conjugated by corresponding antibodies for active targeting nanotherapy. ${ }^{20-22,24,28,35,56,60,63}$ Nanomedicine can restore barrier integrity and prevent cell death by influencing inflammatory pathways ${ }^{20,21,44,60,63,65,70-72}$ and alleviating oxidative stress. $^{28,35,36,42,54,56}$ The influence of nanomedicine on cellular architecture can be assessed by a pragmatic optimized air-liquid interface system, which showed comparable results as those in an in vivo study. ${ }^{90}$

\section{Different Nanomedicine Applications in Treating ALI}

For ALI treatment, nanomedicines are mainly administrated through the intrapulmonary or the intravenous route. For the intrapulmonary route, the agents should be sufficiently potent to penetrate the mucus layer and pass through the cell membrane; two major barriers that affect pulmonary delivery efficiency. ${ }^{91}$ As the mucus layer is rich in negatively charged glycoproteins and phospholipid pulmonary surfactant that can trap cationic agents, it is reasonable to modify the nanomedicines to enhance penetration. ${ }^{62,92}$ For the intravenous route, target delivery to the inflammatory site ensures satisfactory therapeutic efficacy. Targeting strategies include the passive targeting effect called ELVIS (extravasation through leaky vasculature and the subsequent inflammatory cell-mediated sequestration $)^{18}$ and the conjugating of active targeting moieties to the backbone of the nanomedicine. Next, some of the nanomedicine applications in treating ALI through different mechanisms and the therapeutic efficacy are introduced.

\section{Lipid-Based Nanomedicine}

Liposomes are a well-established drug delivery system in the clinical context that are composed of single or multiple concentric lipid bilayers and aqueous compartments. The lipophilic agents are embedded within the phospholipid bilayer, while the aqueous core can encapsulate hydrophilic agents. ${ }^{93}$ Nanostructured lipid carriers (NLCs) or oilloaded solid lipid carriers are the second generation of lipid carriers. The oil core of NLCs offers a variety of fascinating properties, including increased loading capacity, excellent biocompatibility, controlled release compared to the rapid release of liposomes, and feasibility of large-scale production. ${ }^{20,94}$ Anti-inflammatory drugs, ${ }^{20-22,24-26,49,60,61}$ anti-oxidant agents, ${ }^{27,35}$ and neutrophil function inhibitors ${ }^{48,50,51}$ were transformed into nanomedicines to improve their effectiveness and decrease their side effects (Table 2).

The lipophilic antioxidant ( $\alpha$-tocopherol) and the hydrophilic anti-inflammatory agent (Glutathione, GSH or DEX) were encapsulated into liposomes, which showed an advantageous effect in ameliorating lung injury over the free drug. ${ }^{26,27}$ PDE4 inhibitors, rolipram or cilomilast, can repress the activity of neutrophil overactivation, ${ }^{95}$ however, the brain penetration side effects and narrow therapeutic index have restricted their application. ${ }^{50}$ Employing phosphatiosomes to deliver PDE4 inhibitor showed enhance pulmonary surfactant affinity and reduced penetration into the brain; additionally, neutrophil activation was repressed by decreasing the $\mathrm{O}_{2}{ }^{-}, \mathrm{Ca}^{2+}$ content and increasing the cyclic adenosine monophosphate (cAMP) production. ${ }^{50,51}$ Oleic acid $(\mathrm{OA})$ can also inhibit inflammation of activated neutrophils at a certain dose. The changing amount of mineral oil in OA-loaded nanocarriers enabled mean diameters to vary among 105, 153, and 225 $\mathrm{nm}$. Smaller sizes exhibited greater neutrophil uptake to decrease the cell viability and the intracellular calcium level, while larger sizes exhibited greater lung targeting ability than the smaller ones ${ }^{48}$ (Figure 2A). Overproduction of NETs promoted inflammatory pathologies, ${ }^{96}$ and neutrophil elastase (NE) participated in the formation of NETs. ${ }^{97}$ Sivelestat is an NE inhibitor that is clinically used in patients with ALI who develop a systemic inflammatory response. Interbilayer-crosslinked multilamellar vesicles (ICMVs) loading sivelestat (ICMVsivelestat) were readily taken up by neutrophils and inhibited the formation of NETs effectively in vitro. ICMVsivelestat alleviated lung injury by reducing NE and production of other pro-inflammatory cytokines. ${ }^{49}$

To improve the targeting ability of liposomes, mannosylated, ${ }^{25,61}$ and antibody-modified ${ }^{20-22,24,35,60}$ liposomes were developed. Mannosylated (Man) liposomes can target AMs, inhaled liposomes encapsulating dexamethasone palmitate, and Man-cationic liposome/NFкB decoy reduced pro-inflammatory cytokines, and suppress neutrophil infiltration. ${ }^{25,61}$ Surfactant protein A (SP-A) is a type of pulmonary SP that is mostly expressed in type II alveolar epithelial cells but is rarely expressed in extrapulmonary tissues and organs. ${ }^{24}$ SP-A nanobodyconjugated immune-liposomes delivering glucocorticoids showed good lung-targeting specificity and decreased the 


\begin{tabular}{|c|c|c|c|c|c|c|c|c|c|c|c|}
\hline 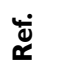 & 㝏 & $\lesssim$ & 물 & $\overline{\check{n}}$ & $\underset{\sigma}{\sigma}$ & $\stackrel{\mathbb{g}}{\mathcal{F}^{\prime}}$ & 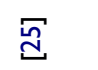 & $\overline{\bar{\sigma}}$ & $\mathbb{\Xi}$ & $\underset{\Xi}{\mathbb{Z}}$ & 足 \\
\hline 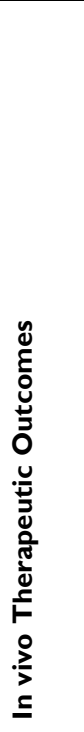 & 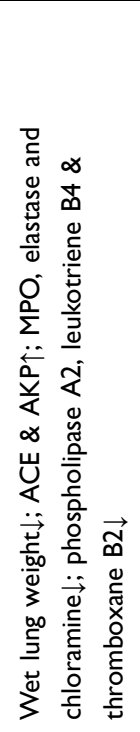 & 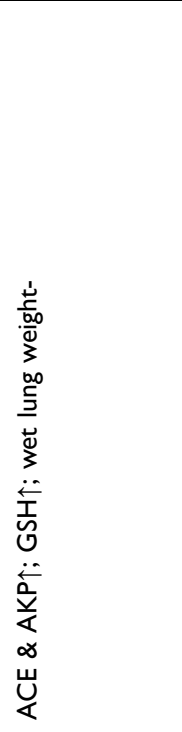 & 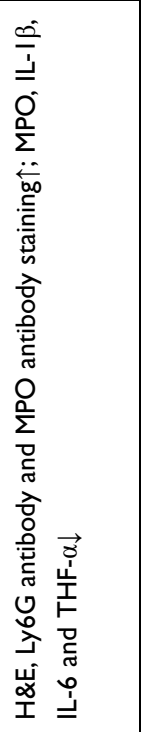 & 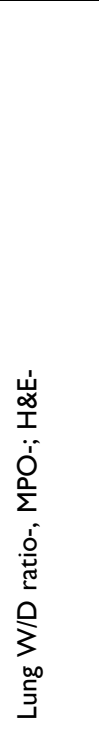 & 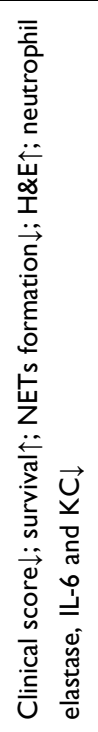 & 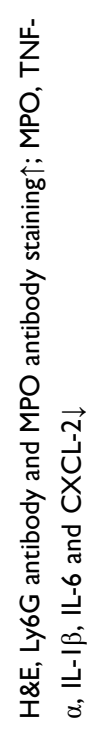 & 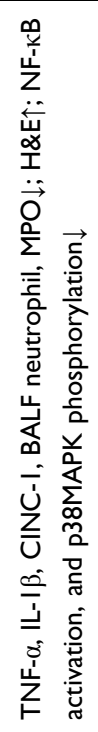 & 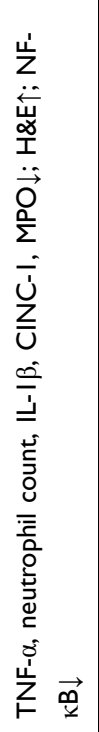 & 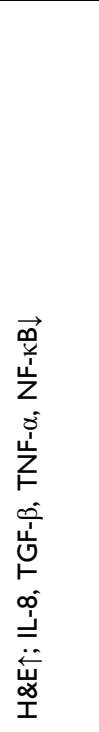 & 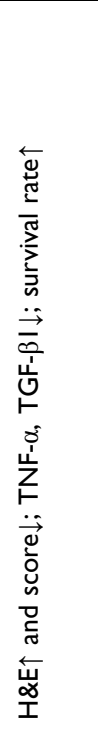 & 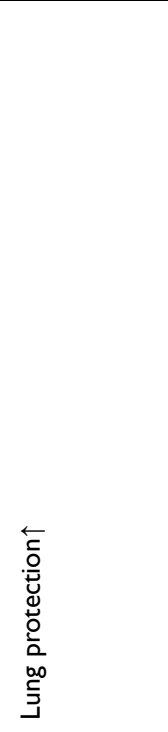 \\
\hline 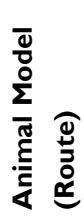 & 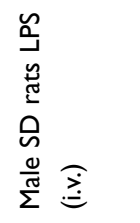 & 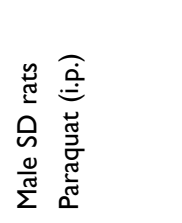 & 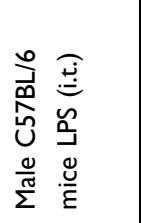 & 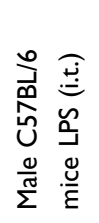 & 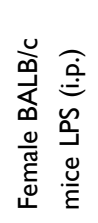 & 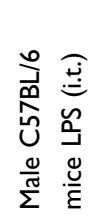 & 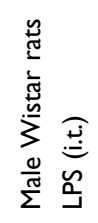 & 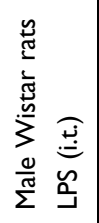 & 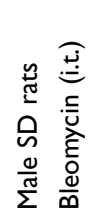 & 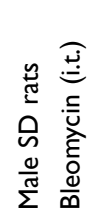 & 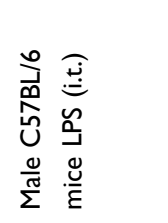 \\
\hline 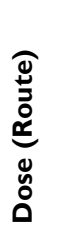 & 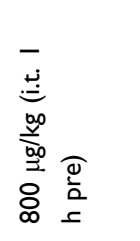 & 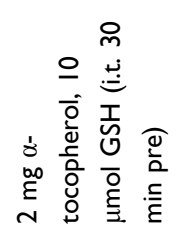 & 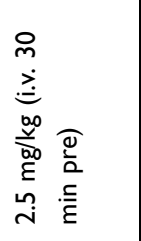 & 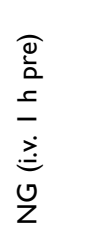 & 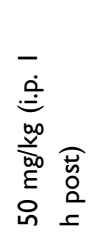 & 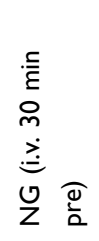 & 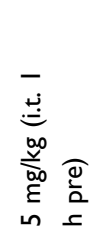 & 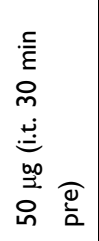 & 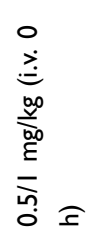 & 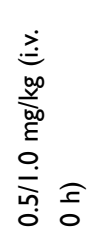 & 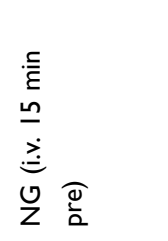 \\
\hline 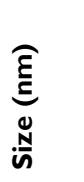 & $\begin{array}{l}\tilde{m} \\
+1 \\
\frac{\tilde{N}}{N}\end{array}$ & $\begin{array}{l}\stackrel{\infty}{n} \\
+1 \\
\stackrel{\rho}{m}\end{array}$ & 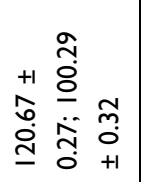 & 芒 & $\begin{array}{l}\simeq \\
+1 \\
\stackrel{0}{0}\end{array}$ & 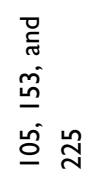 & $\begin{array}{l}a \\
\dot{b} \\
+1 \\
\stackrel{o}{0}\end{array}$ & $\frac{8}{1}$ & $\stackrel{\circ}{\circ}$ & $\begin{array}{l}\infty \\
m \\
+1 \\
\stackrel{\infty}{0} \\
\stackrel{0}{0}\end{array}$ & $\begin{array}{l}\stackrel{\sim}{+} \\
+ \\
+1 \\
\infty \\
\stackrel{0}{\infty}\end{array}$ \\
\hline 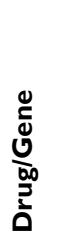 & 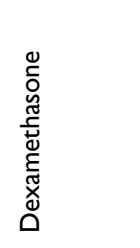 & 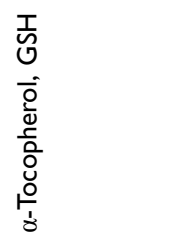 & 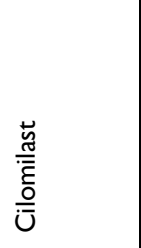 & 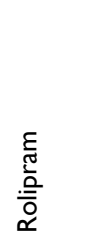 & 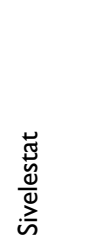 & $\delta$ & 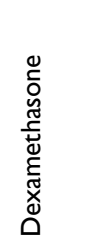 & 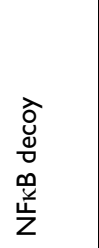 & 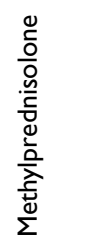 & 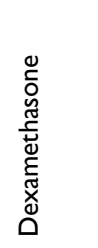 & $\begin{array}{l}\stackrel{+}{m} \\
\stackrel{\dot{m}}{\vec{u}}\end{array}$ \\
\hline 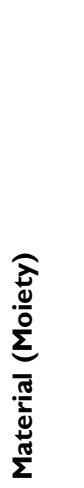 & $\begin{array}{l}\text { U } \\
\text { à } \\
0\end{array}$ & $\begin{array}{l}0 \\
\frac{0}{0} \\
0\end{array}$ & 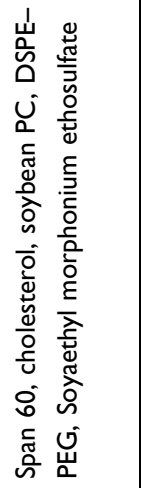 & 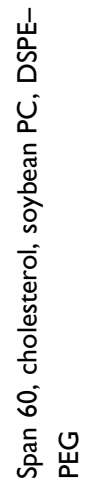 & 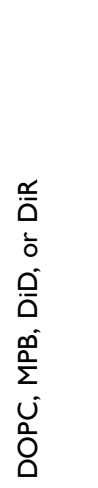 & 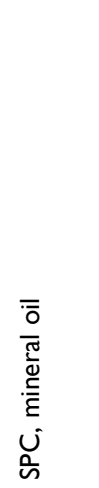 & 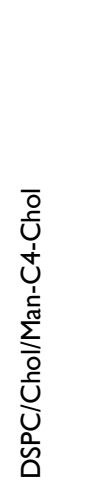 & 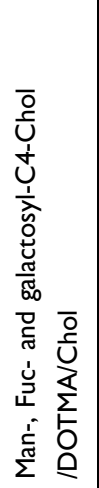 & 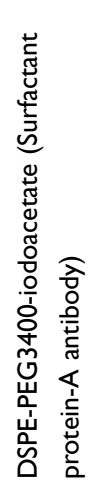 & 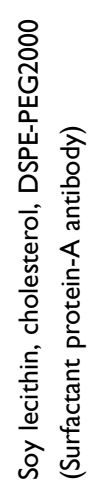 & 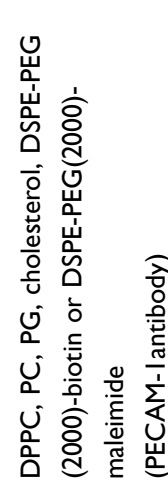 \\
\hline
\end{tabular}




\begin{tabular}{|c|c|c|}
\hline 럼 & $\overline{\bar{\Sigma}}$ & శ్ర \\
\hline 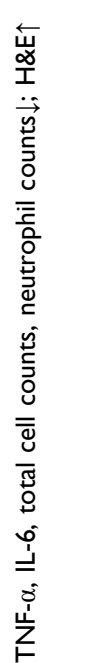 & 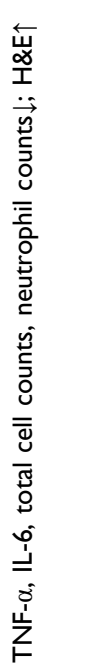 & 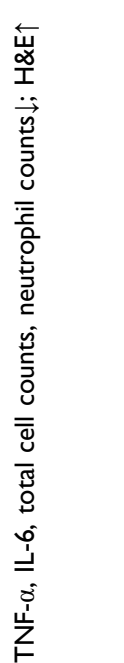 \\
\hline 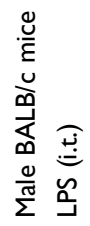 & 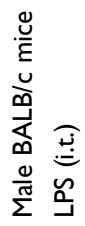 & 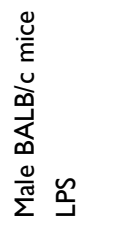 \\
\hline 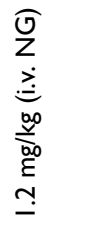 & 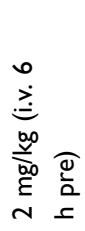 & $\begin{array}{l}\widehat{c} \\
0 \\
\dot{z} \\
\stackrel{E}{0} \\
\dot{z}\end{array}$ \\
\hline 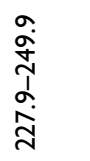 & 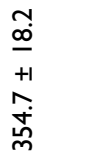 & 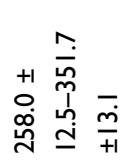 \\
\hline 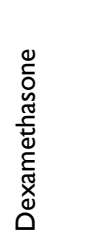 & 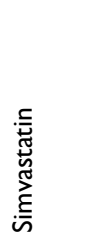 & 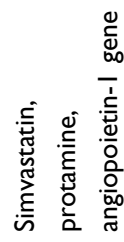 \\
\hline 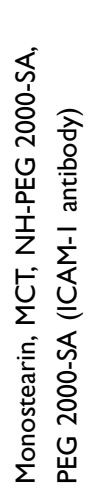 & 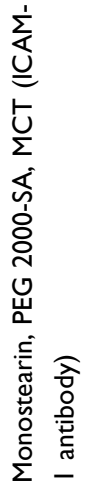 & 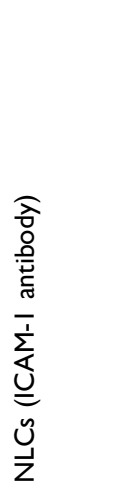 \\
\hline
\end{tabular}

cytokine level in bronchoalveolar lavage fluid (BALF). ${ }^{22,24}$ NLCs can be incorporated into lung endothelial cells via caveolar vesicles, and thus possess endothelial-protective effects. ${ }^{98}$ Conjugating ICAM-1 antibody to NLCs endowed its active targeting ability to lung endothelium, and the size and zeta potential of the liposomes were correlated with the therapeutic effects. ${ }^{20,21,60}$ The larger NLCs (337.8 nm) loading simvastatin exhibited ideal lungtargeting characteristics ${ }^{21}$ (Figure 2B). Other lung-targeted ternary NLCs loaded with simvastatin, protamine (Pro), and the angiopoietin-1 (Ang-1) gene with a larger size $(357.1 \mathrm{~nm})$ also showed better improvements. ${ }^{60}$ The anionic NLCs exhibited higher cellular uptake and stronger pulmonary distribution, showing significant antiinflammatory efficacy. ${ }^{20}$ PECAM-1 binds to the endothelium and is internalized via the noncanonical cell adhesion molecule (CAM)-mediated endocytic pathway ${ }^{99}$ and can be adopted to endow lung-targeting ability. PEGylated liposomes conjugated with anti-PECAM-1 loaded with EUK-134 accumulated in the lungs after i.v. administration, inhibited cytokine-induced inflammatory activation, and provided $>60 \%$ protection against lung edema in the endotoxin-stimulated mouse model. ${ }^{35}$ Recently, a soft nanobot composed of double micellar microemulsions has been developed, which possess the capability of active nanodrug delivery to strictures of air-liquid interface, and this could become a promising technology for therapeutic carriers and targeted delivery to ALI/ARDS. ${ }^{100}$

\section{Polymeric Nanomedicine}

Polymeric nanomedicines can be engineered from natural or synthetic polymers, ${ }^{101}$ most of which are biodegradable and biocompatible. Synthetic polymers are usually coated with polyethylene glycol (PEG) to reduce their toxicity and increase their solubility. Their high drug-loading capacity makes them favorable carriers for in vivo therapies; ${ }^{102}$ they deliver drugs ${ }^{19,23,28-30,34,70-72}$ and genes $^{31,33,53,62-65,68-73}$ to the targeted site or act as therapeutic agents by themselves ${ }^{52,67}$ for ALI treatment (Table 3).

Poly-lactic-co-glycolic acid (PLGA) is the most commonly used polymer with good biodegradability and biocompatibility. $^{103}$ The PLGA nanoparticle-containing ruthenium red was used in the ventilator-induced lung injury (VILI) model via inhalation. This nanomedicine reacted through the alveolar macrophages and the capillary endothelial cells, blocked calcium signaling, and inhibited vascular permeability in ex vivo ventilation-perfusion 
A

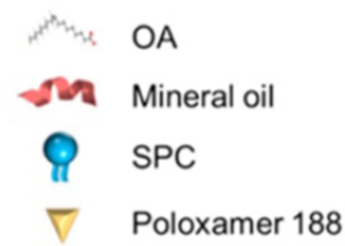

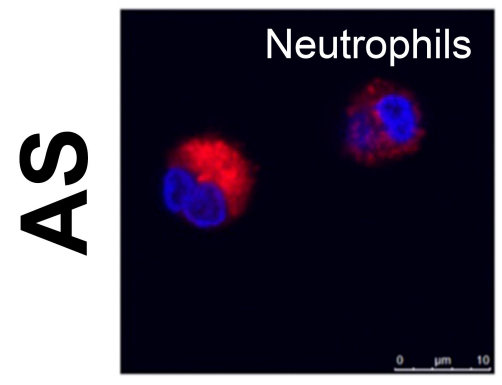
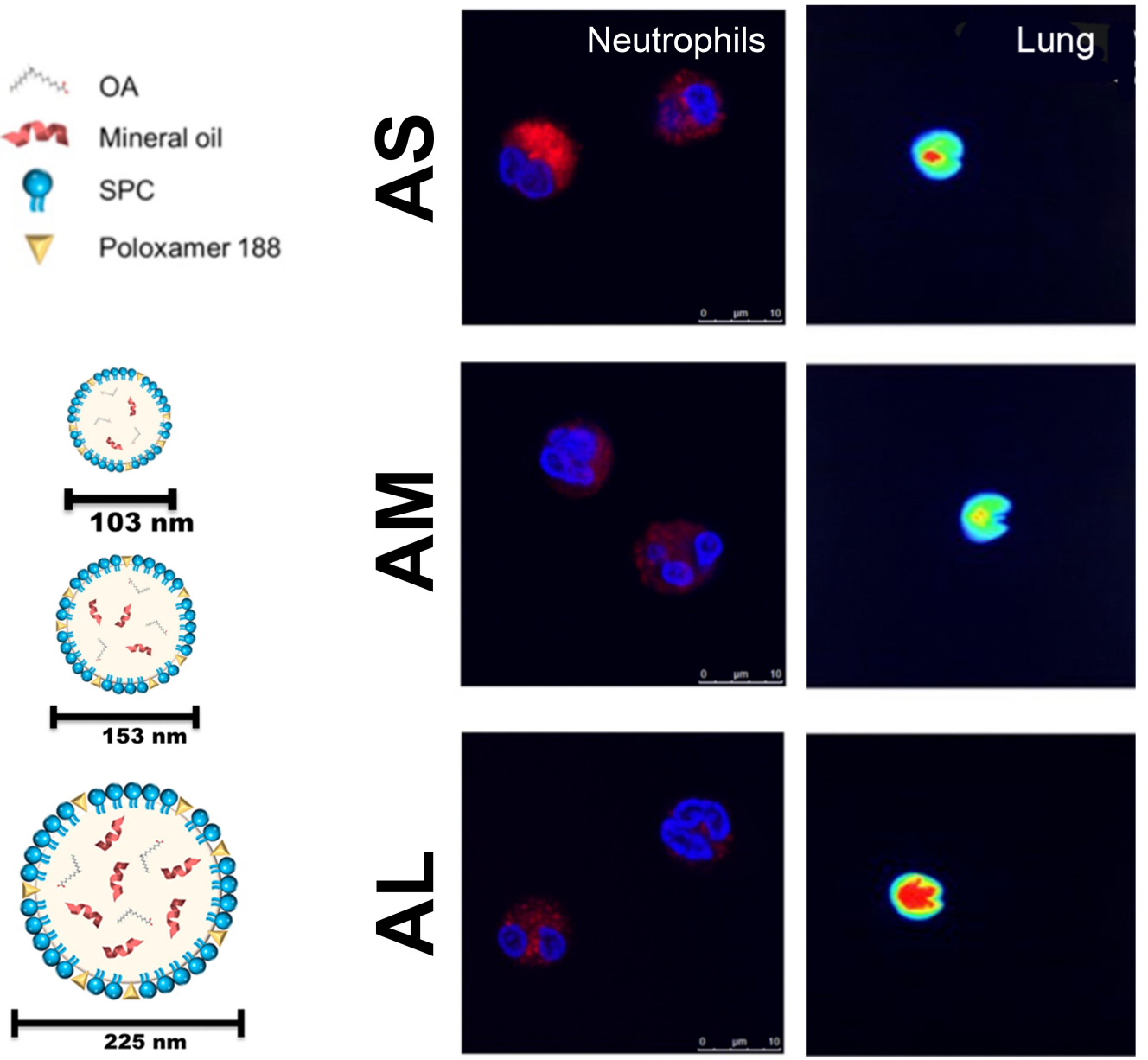

$12 \mathrm{~h}$ $24 \mathrm{~h}$

B

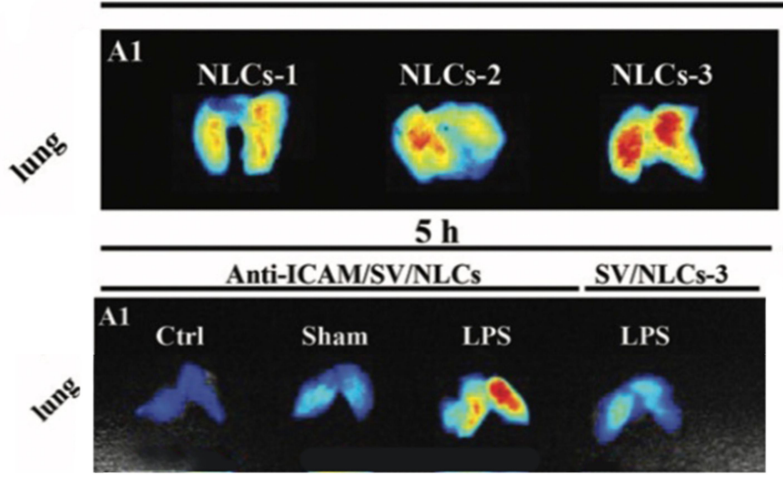

MAX

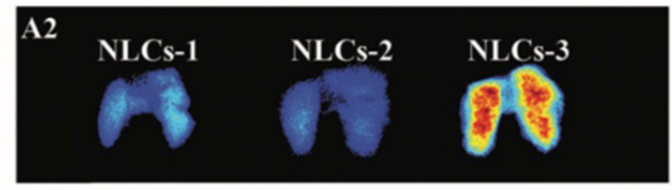

$24 \mathrm{~h}$

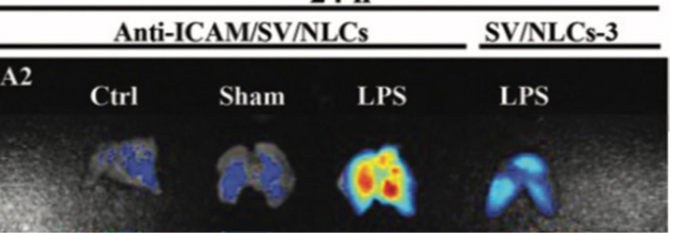

Figure 2 Lipid-based nanomedicine. (A) Various diameters of OA-loaded nanocarriers showed different characteristics. Smaller sizes (AS) exhibited greater neutrophil uptake, while larger sizes (AL) exhibited greater lung targeting ability. Note: Reproduced with the permission from Yu HP, Liu FC, Umoro A et al. Oleic acid-based nanosystems for mitigating acute respiratory distress syndrome in mice through neutrophil suppression: how the particulate size affects therapeutic efficiency. JNanobiotechnology. 2020;18(I):25. Copyright (2020) Journal of Nanobiotechnology under Creative Commons Attribution 4.0 International License. ${ }^{48}$ (B) The larger NLCs-3 (337.8 nm) exhibited greater lung retention ability. Conjugating ICAM-I antibody to NLC endowed it active targeting ability to lung endothelium, and showed better lung distribution. Note: Reproduced with the permission from Li SJ, Wang XJ, Hu JB et al. Targeting delivery of simvastatin using ICAM-I antibody-conjugated nanostructured lipid carriers for acute lung injury therapy. Drug Deliv. 2017;24(I):402-4I3. Copyright (20I7) Drug Delivery under Creative Commons Attribution 4.0 International License. ${ }^{21}$

experiments. ${ }^{30}$ Murine sialic acid-binding immunoglobulin-like lectin-E (Siglec-E) is an immunomodulatory receptor that negatively regulates acute inflammatory responses. PLGA nanoparticles decorated with $\operatorname{di}(\mathrm{a} 2 \rightarrow 8)$
N-acetylneuraminic acid (a2,8 NANA-NP), a natural Siglec ligand, could induce enhanced oligomerization of Siglec-E receptors on macrophages, blocking the production of inflammatory cytokines in a Siglec-E-dependent 


\begin{tabular}{|c|c|c|c|c|c|c|c|c|c|c|c|c|}
\hline $\begin{array}{l}\dot{\Phi} \\
\ddot{x}\end{array}$ & 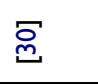 & 鹿 & ন্ড & ฮ & $\stackrel{\Xi}{\Xi}$ & $\stackrel{\text { d্ }}{\mathbf{d}}$ & 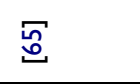 & 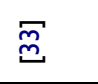 & $\overline{\bar{m}}$ & 氮 & 守 & 氙 \\
\hline 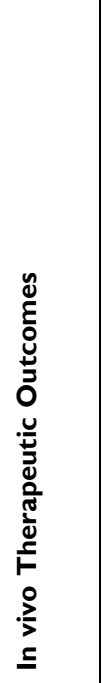 & 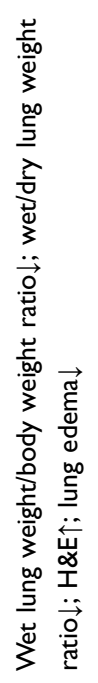 & 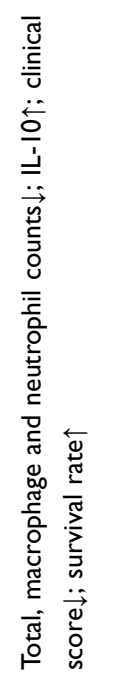 & 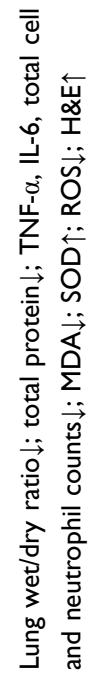 & 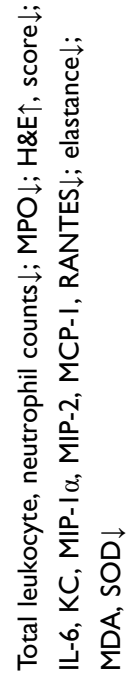 & 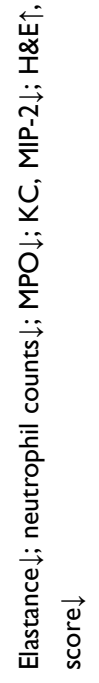 & 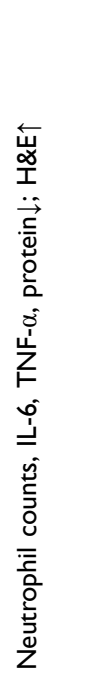 & 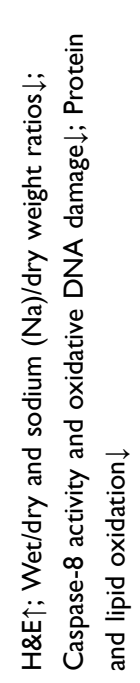 & 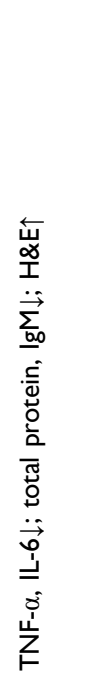 & 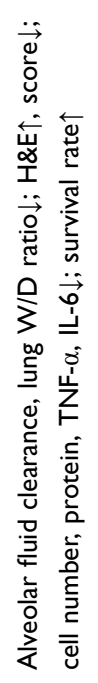 & 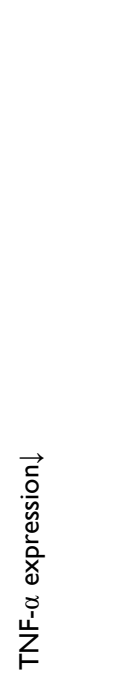 & 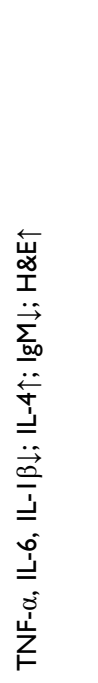 & 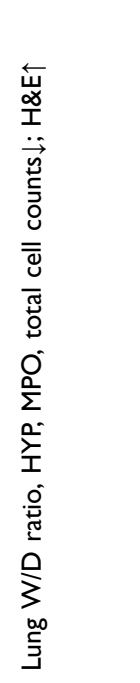 \\
\hline 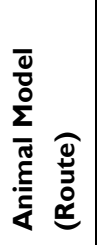 & 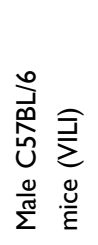 & 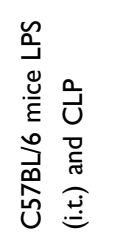 & 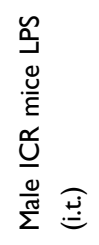 & 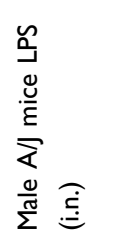 & 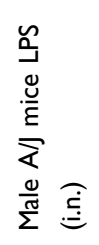 & 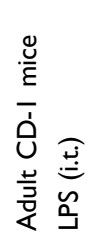 & 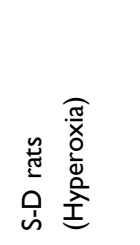 & 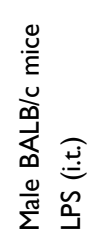 & 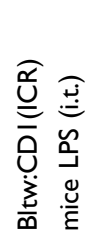 & 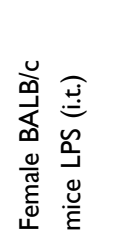 & 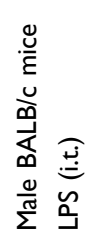 & 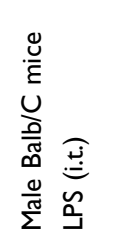 \\
\hline 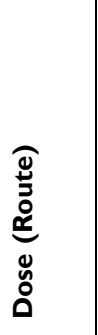 & $\begin{array}{l}\underset{\hat{\dot{E}}}{\stackrel{\underline{E}}{E}} \\
\underset{E}{\underline{E}}\end{array}$ & 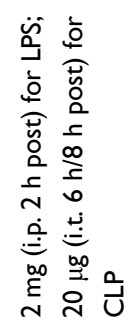 & 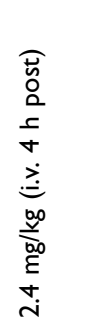 & 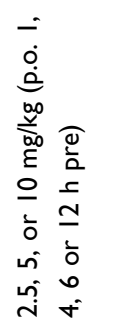 & 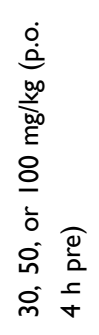 & 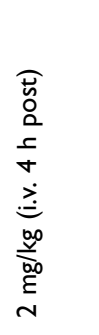 & 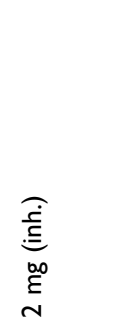 & 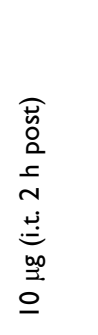 & 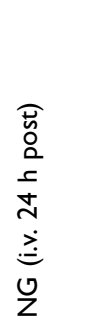 & 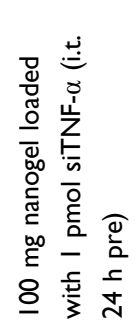 & 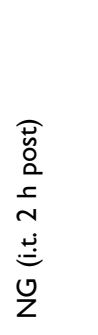 & 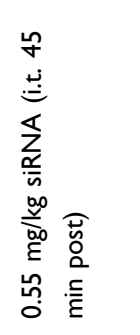 \\
\hline 芯 $\widehat{\underline{\varepsilon}}$ & ষ্ল & 오 & $\begin{array}{ll}+1 & R \\
\text { N } & 0 \\
\infty & 0 \\
\end{array}$ & $\begin{array}{l}\hat{+1} \\
\bar{j}\end{array}$ & $\begin{array}{l}+1 \\
\stackrel{8}{0}\end{array}$ & 으 & $\stackrel{+1}{\stackrel{+}{0}} \stackrel{2}{\circ}$ & $\frac{8}{1}$ & i & ì্ & $\stackrel{\underline{m}}{=}$ & $\frac{9}{1}$ \\
\hline 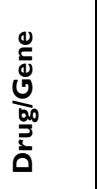 & 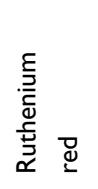 & & $\begin{array}{l}\frac{a}{0} \\
\hat{5} \\
\frac{1}{3} \\
0\end{array}$ & 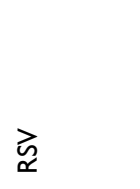 & 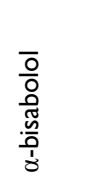 & $\begin{array}{l}\overline{\dot{S}} \\
\text { 足 }\end{array}$ & 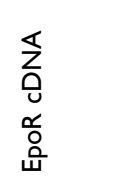 & $\begin{array}{l}\nwarrow \\
0 \\
0 \\
\frac{\tilde{z}}{\bar{z}} \\
\frac{\pi}{\alpha}\end{array}$ & 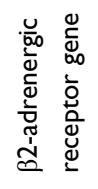 & 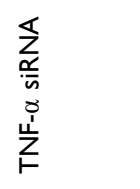 & 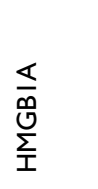 & $\begin{array}{l}\frac{\nwarrow}{\alpha} \\
\frac{x}{\bar{n}} \\
\frac{1}{\bar{\alpha}} \\
\frac{\Sigma}{a}\end{array}$ \\
\hline 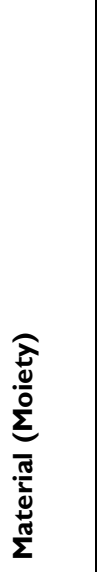 & 㜽 & 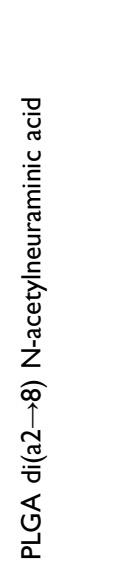 & 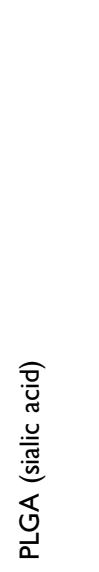 & 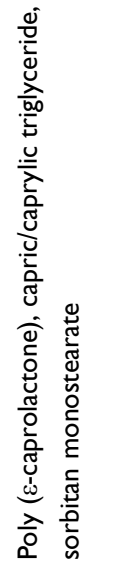 & 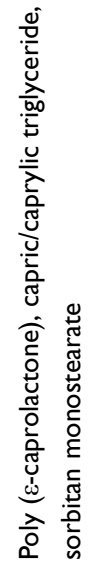 & 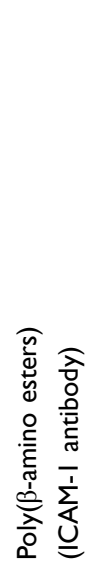 & 芯 & 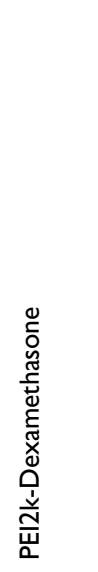 & $\begin{array}{l}\overleftarrow{z} \\
\text { 总 }\end{array}$ & 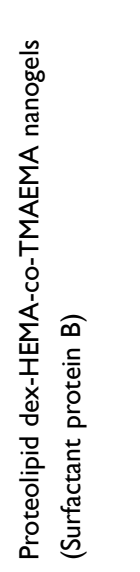 & 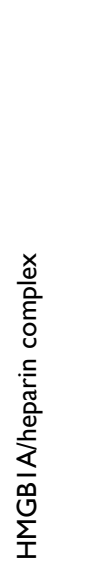 & 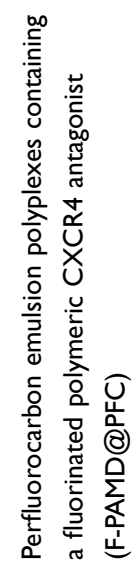 \\
\hline
\end{tabular}




\begin{tabular}{|c|c|c|c|c|c|c|c|c|c|}
\hline$\dot{\mathscr{\Phi}}$ & $\underset{\Xi}{\overparen{S}}$ & $\sqrt[\widetilde{\Omega}]{\Omega}$ & $\widetilde{\Xi}$ & 实 & $\bar{\Sigma}$ & $\Phi$ & $\bar{c}$ & 䒜 & $\stackrel{\mathbb{\infty}}{\stackrel{\infty}{g}}$ \\
\hline 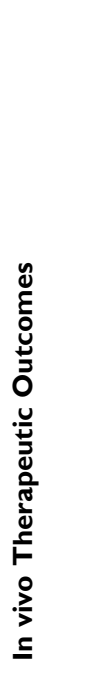 & 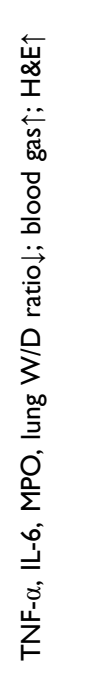 & 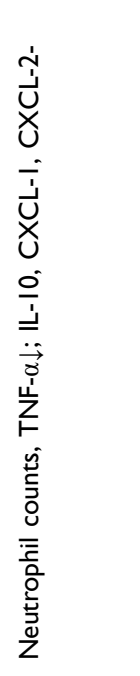 & 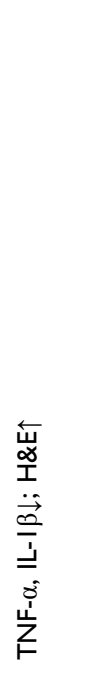 & 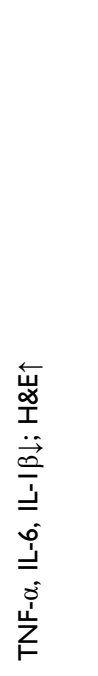 & 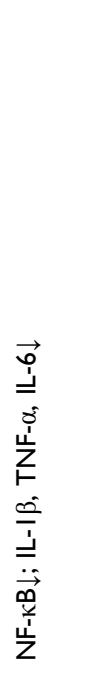 & 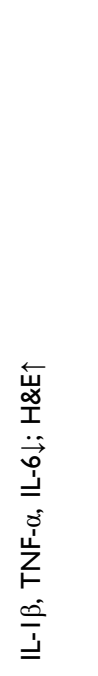 & 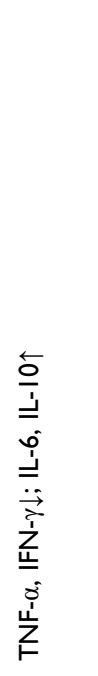 & 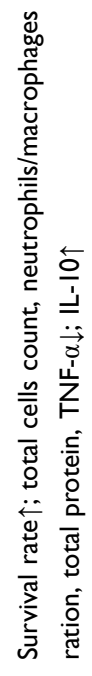 & 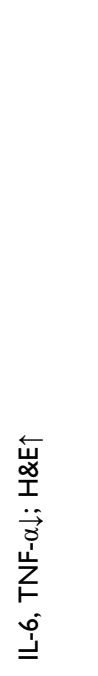 \\
\hline 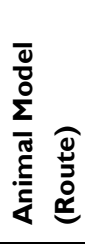 & 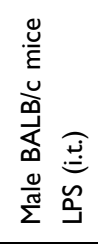 & 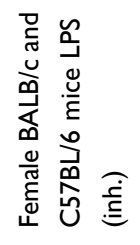 & 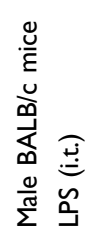 & 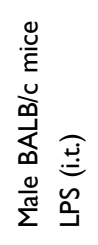 & 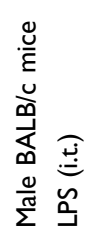 & 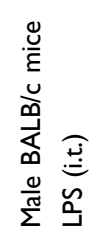 & 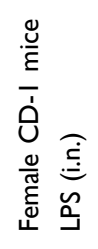 & 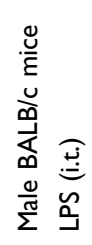 & 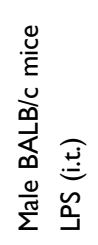 \\
\hline 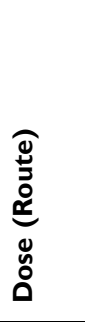 & 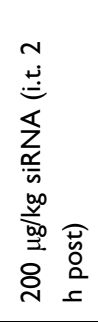 & 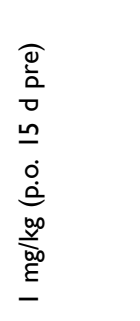 & 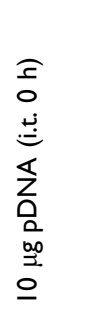 & 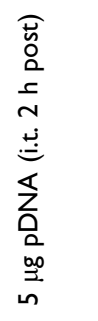 & 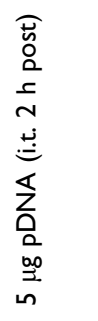 & 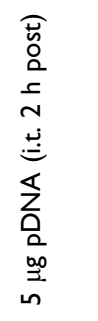 & 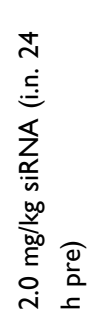 & 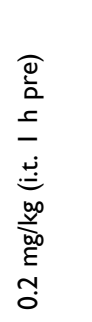 & 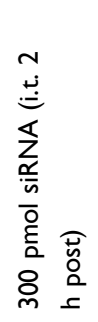 \\
\hline 芯 $\widehat{\underline{\varepsilon}}$ & $\frac{\circ}{1}$ & & 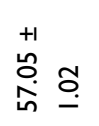 & $\frac{\sigma}{\infty}$ & $\begin{array}{l}+1 \\
\stackrel{+1}{ \pm} \\
\stackrel{0}{\simeq}\end{array}$ & $\frac{\text { ㄱ }}{1}$ & $\frac{\circ}{\frac{8}{1}}$ & $\underset{i}{\stackrel{2}{1}}$ & in \\
\hline 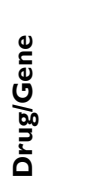 & 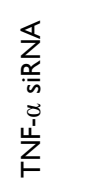 & & 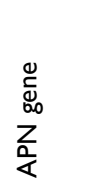 & 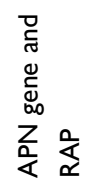 & 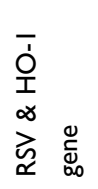 & 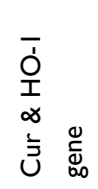 & 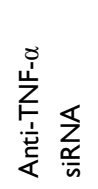 & $\frac{a}{a}$ & 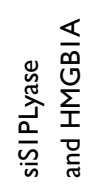 \\
\hline 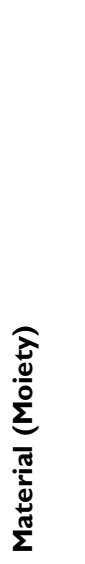 & 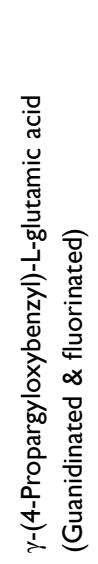 & 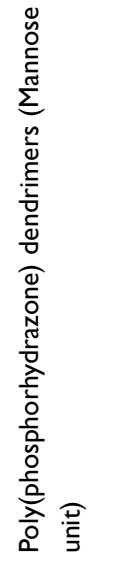 & 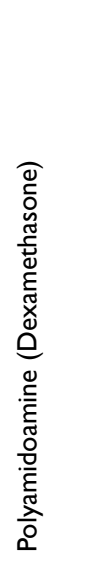 & 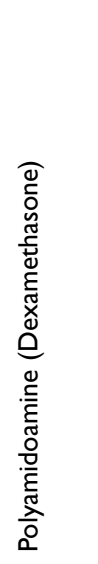 & 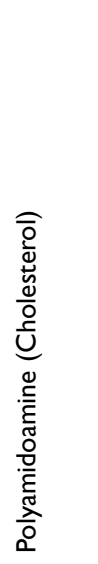 & 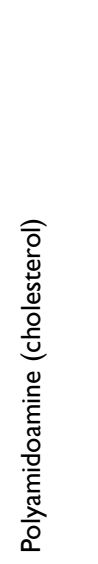 & 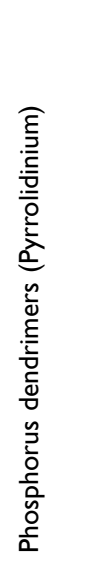 & 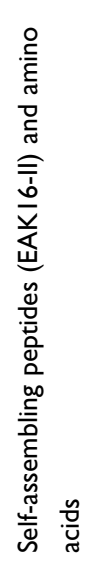 & 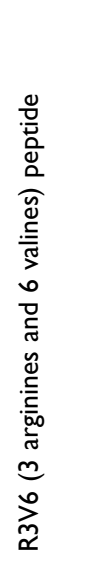 \\
\hline
\end{tabular}




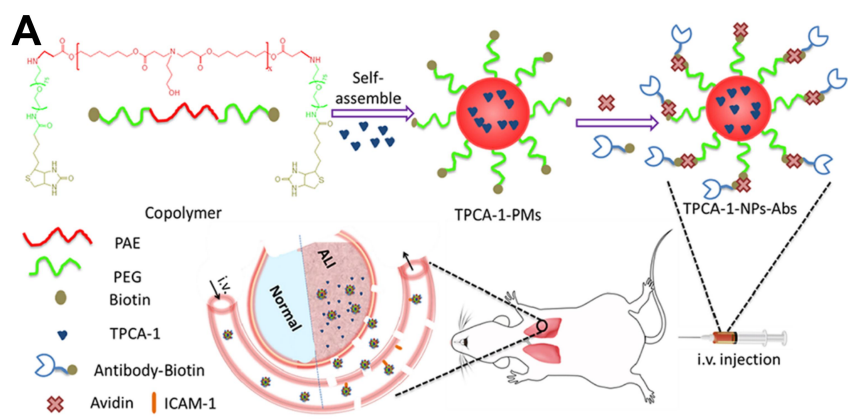

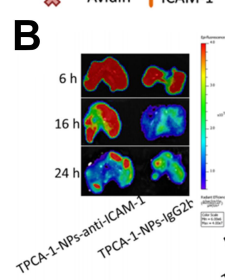

E

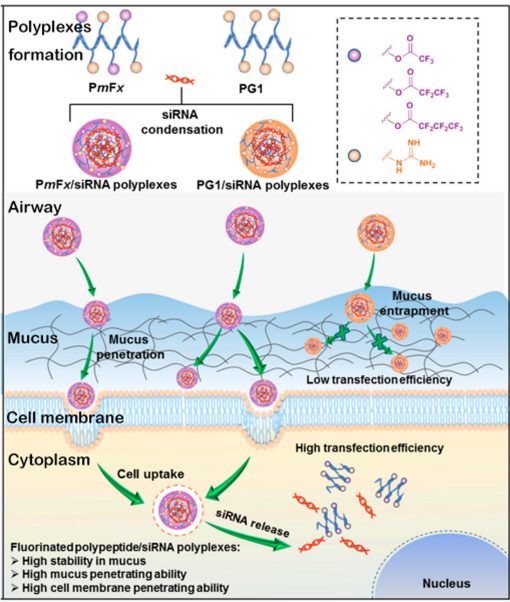

D

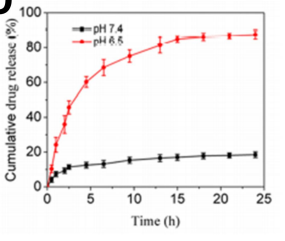

$\mathbf{F}$

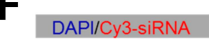

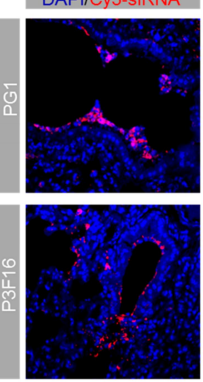

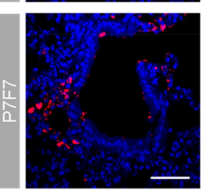

G
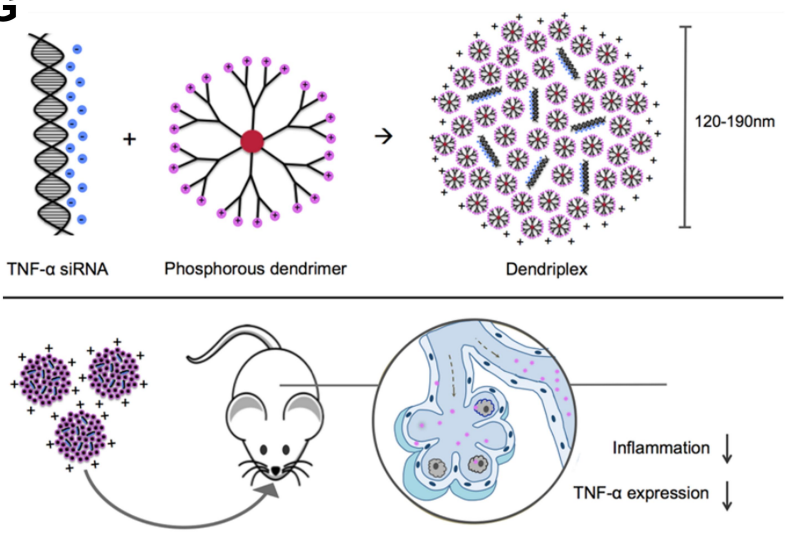

Intranasal delivery to inflammed lungs

Figure 3 Polymeric nanomedicine. (A) Anti-ICAM-I antibody decorated poly( $\beta$-amino esters) targeted to mouse lungs. (B and C) The fluorescence of FITC-labeled nanoparticles and Cy5-labeled TPCA-I was measured using in vivo imaging systems (IVIS). (D) The cumulative release of TPCA-I at different PH. Note: Reprinted with permission from Zhang CY, Lin W, Gao J et al. pH-Responsive Nanoparticles Targeted to Lungs for Improved Therapy of Acute Lung Inflammation/Injury. ACS Appl Mater Interfaces. 2019;1 (18):16380-16390. Copyright (2019) American Chemical Society. ${ }^{28}$ (E) Fluorinated and guanidinated bifunctional helical polypeptides enhanced the mucus and cell membrane penetration. (F) Distribution of polyplexes in lung epithelial tissues. Note: Reprinted with the permission from Ge C, Yang J, Duan S, Liu Y, Meng F, Yin L. Fluorinated alpha-Helical Polypeptides Synchronize Mucus Permeation and Cell Penetration toward Highly Efficient Pulmonary siRNA Delivery against Acute Lung Injury. Nano Lett. 2020;20(3): 1738-1746. Copyright (2020) American Chemical Society. ${ }^{62}$ (G) Cationic phosphorus dendrimer nanocomplexes delivering anti-TNF- $\alpha$ siRNA to inhibited TNF- $\alpha$ with high efficiency. Note: Reprinted with the permission from Bohr A, Tsapis N, Andreana I et al. Anti-Inflammatory Effect of Anti-TNF-alpha SiRNA Cationic Phosphorus Dendrimer Nanocomplexes Administered Intranasally in a Murine Acute Lung Injury Model. Biomacromolecules. 20I7;18(8):2379-2388. Copyright (2017) American Chemical Society. ${ }^{73}$ 
manner. ${ }^{67}$ Oxidative stress plays an important role in $\mathrm{ALI}^{104}$ and mitochondria are the main source of ROS production. Sialic acid (SA)-functionalized PEG-PLGA microspheres loaded with triphenylphosphonium (TPP) cation-modified curcumin (Cur) were utilized as mitochondria-targeting ALI therapy. The microsphere's size was larger than $800 \mathrm{~nm}$, thus enabling good lung distribution, and the SA modification exhibited an ideal lung-targeted characteristic. $^{29}$ Using poly(E-caprolactone) to construct lipid-core nano-capsules (LNCs) and encapsulated $\alpha$ bisabolol ( $\alpha$-bis) or resveratrol (RSV) into LNCs can minimize drug oxidation, improving internal absorption and showing satisfactory therapeutic effects. ${ }^{19,23}$ The inflammatory microenvironment of ALI has the feature of a low $\mathrm{pH}$; poly( $\beta$-amino esters) have a sharp acid-sensitive segment; bio-conjugating anti-ICAM-1 antibodies enable satisfying lung targeting and extended circulation. The $\mathrm{pH}-$ responsive nanoparticles can load anti-inflammatory agent TPCA-1 at a high content $(24 \%, \mathrm{w} / \mathrm{w})$. The accumulative release of TPCA-1 increases from less than $20 \% 24 \mathrm{~h}$ at $\mathrm{pH} 7.4$ to approximately $90 \% 15 \mathrm{~h}$ at $\mathrm{pH} 6.5^{28}$ (Figure 3A-D).

Polymeric nanoparticles are also attractive gene carriers for ALI therapy. ${ }^{91}$ Nebulized PLGA bearing erythropoietin receptor (EpoR) complementary DNA (cDNA) nanoparticles upregulated pulmonary EpoR expression and downstream signal transduction to counteract the inflammation in hyperoxia-induced lung injury in rats. ${ }^{65}$ Modifying low molecular weight polyethyleneimine (PEI) with dexamethasone improves its translocation into the nucleus and its gene transfection efficiency. ${ }^{33}$ PEI carries $\beta 2$-adrenergic receptor $(\beta 2 \mathrm{AR})$ gene, which regulates alveolar ion and fluid transport, ${ }^{105}$ dramatically improving alveolar clearance and decreasing lung fluid content without major adverse effects. ${ }^{31}$ Merckx et al used Curosurf ${ }^{\circledR}$, a clinically used pulmonary surfactant (PS), as the shell and siRNA-loaded nanosized dextran nanogels as the core to form hybrid nanoparticles for inhalation therapy. The PS shell improved the particle stability, and the intracellular siRNA delivery was enhanced by inserting SP-B into the phospholipid shell. ${ }^{63}$ High mobility group box-1 box A (HMGB1A) may be captured in the mucus layer due to its positive charges when administered intratracheally; heparin has negative charges and an anti-inflammatory effect. The HMGB1A/heparin complex was obtained using electrostatic interactions, and reduced proinflammatory cytokines synergically. ${ }^{64}$ Fluoropolymers in the form of perfluorocarbon (PFC) nano-emulsions could improve cellular siRNA delivery. ${ }^{106}$ Wang et al reported a PFC emulsion polyplex as a gene carrier, containing fluorinated polymeric CX-C chemokine receptor type 4 (CXCR4) antagonist and delivered plasminogen activator inhibitor-1 (PAI-1) siRNA to inhibit CXCR4 and PAI-1 for combined therapy. ${ }^{53}$ Another way to enhance mucuspenetrating ability is to develop bifunctional guanidineand fluorine-decorated helical polypeptides. The fluorinated polypeptides dramatically enhanced mucus permeation capability by approximately 240 -fold, while the guanidine domain and the $\alpha$-helix structure facilitated trans-membrane siRNA delivery. Using the topperforming polypeptide, P7F7, to administer TNF- $\alpha$ siRNA intratracheally produced highly efficient ( $\sim 96 \%)$ gene knockdown ${ }^{62}$ (Figure $3 \mathrm{E}$ and F).

Dendrimers are regularly branched macromolecules that are usually developed as forming dendrimer-drug conjugates or as gene carriers. $^{101}$ Inspired by Mycobacterium tuberculosis, Blattes et al designed manno-dendrimers that mimicked the bioactive supramolecular structure of mannose-capped lipoarabinomannan. The manno-dendrimers could target the C-type lectin receptor DC-specific intercellular adhesion molecule 3-grabbing nonintegrin (DC-SIGN), thus inhibiting neutrophil recruitment significantly. ${ }^{52}$ Adiponectin (APN) is an anti-inflammatory and cytoprotective adipokine. ${ }^{107}$ Delivery of APN using dexamethasone conjugated polyamidoamine (PAM-D) upregulated APN expression. ${ }^{72}$ In a subsequent study, the RAGE-antagonist peptide (RAP) increased the gene delivery efficiency of PAM-D, and the RAP inhibited the RAGE-signal to show antiinflammatory effects. ${ }^{69}$ Cholesterol-conjugated polyamidoamine micelles could deliver pHO-1 (heme-oxygenase -1 plasmid) along with RSV or Cur, in which pHO-1 induced HO-1 expression to decrease pro-inflammatory cytokines, and RSV or Cur inhibited the inflammatory reactions synergically. ${ }^{70,71}$ The phosphorus dendrimers have been shown to have more efficiency in the cellular delivery of siRNA ${ }^{108}$ and exhibited anti-inflammatory properties simultaneously. ${ }^{109}$ Compared with morpholinium-containing dendriplexes, pyrrolidinium-decorating dendriplexes demonstrated a stronger siRNA complexation, and the higher cellular uptake enabled an enhanced silencing efficiency of TNF- $\alpha^{73}$ (Figure 3G).

The biocompatibility, biodegradability, and the lack of immune response properties of self-assembling peptides make them ideal drug carriers and regenerative medicines. ${ }^{110}$ Self-assembling R3V6 peptides with 
Table 4 Inorganic Nanomedicine

\begin{tabular}{|c|c|c|c|c|c|}
\hline $\begin{array}{l}\text { Material } \\
\text { (Moiety) }\end{array}$ & $\begin{array}{l}\text { Size } \\
(\mathrm{nm})\end{array}$ & Dose (Route) & $\begin{array}{l}\text { Animal Model } \\
\text { (Route) }\end{array}$ & In vivo Therapeutic Outcomes & Ref. \\
\hline $\begin{array}{l}\text { GNPs } \\
\text { (CLPFFD) }\end{array}$ & $\begin{array}{l}17.5 \\
\pm 0.6\end{array}$ & $\begin{array}{l}50 \text { pmol (i.t. } 2 \\
\text { h pre) }\end{array}$ & $\begin{array}{l}\text { Male C57BL/6] } \\
\text { mice LPS (i.t.) }\end{array}$ & $\begin{array}{l}\text { H\&E } \uparrow \text {, score } \downarrow \text {; total cell, neutrophil, macrophage, lymphocyte } \downarrow \text {; } \\
\text { regulatory T cells }\end{array}$ & {$[41]$} \\
\hline $\begin{array}{l}\text { GNPs } \\
\text { (CLPFFD) and } \\
\text { (CSE) }\end{array}$ & $\begin{array}{l}23.9 \\
\pm 0.3\end{array}$ & 500 nM (i.t. Ih pre) & $\begin{array}{l}\text { Male C57BL/6 } \\
\text { mice LPS (i.n.) }\end{array}$ & $\begin{array}{l}\text { Total cell, neutrophil, protein } \downarrow ; \text { TNF- } \alpha, \text { KC, IL-6, CCL-2 } \downarrow ; \text { H\&E } \uparrow \text {, } \\
\text { score } \downarrow\end{array}$ & [40] \\
\hline $\begin{array}{l}\text { GNPs } \\
\text { (CLPFFD) }\end{array}$ & $\begin{array}{l}26.9 \\
\pm 0.8\end{array}$ & 500 nM (i.t. I h pre) & $\begin{array}{l}\text { Male C57BL/6 } \\
\text { mice LPS (i.n.) }\end{array}$ & $\begin{array}{l}\text { Total cell, neutrophil } \downarrow ; \text { KC, CCL- } 2 \downarrow \text {; lung W/D ratio, lung } \\
\text { protein } \downarrow ; \text { H\&E } \uparrow \text {, score } \downarrow\end{array}$ & [39] \\
\hline $\begin{array}{l}\text { GNPs } \\
\text { (CLPFFD) }\end{array}$ & $\begin{array}{l}18.8 \\
\pm 0.1\end{array}$ & 500 nM (i.t. 2 h pre) & $\begin{array}{l}\text { Male C57BL/6 } \\
\text { mice LPS (i.t.) }\end{array}$ & 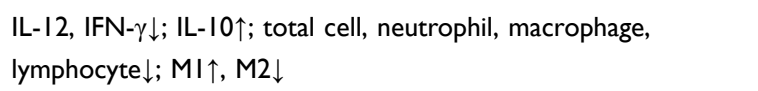 & [37] \\
\hline $\mathrm{CeO}_{2} @ \mathrm{SiO}_{2}$ & $\begin{array}{l}220 \pm \\
5\end{array}$ & $\begin{array}{l}0.6 \mathrm{mg} / \mathrm{kg} \text { (p.o. } 0, \mathrm{I}, \\
3,24 \mathrm{~h} \text { post) }\end{array}$ & $\begin{array}{l}\text { Male Wistar rats } \\
\text { LPS (i.p.) }\end{array}$ & $\mathrm{H} \& \mathrm{E} \uparrow ; \mathrm{ROS} \downarrow ; \mathrm{TNF}-\alpha, \mathrm{IL}-6, \mathrm{CXCL}-2 \downarrow ; \mathrm{V}^{\prime} \mathrm{O}_{2}, \mathrm{~V}_{\mathrm{T}}, \mathrm{V}_{\mathrm{E}}^{\prime} \uparrow$ & [43] \\
\hline $\begin{array}{l}\mathrm{Se} @ \mathrm{SiO}_{2} \mathrm{PVP} \\
\text { coated }\end{array}$ & $\sim 55$ & $\begin{array}{l}\mathrm{I} \mathrm{mg} / \mathrm{kg} \text { (i.p. every } \\
24 \mathrm{~h})\end{array}$ & $\begin{array}{l}\text { Male S-D rats } \\
\text { Paraquat (i.g.) }\end{array}$ & $\begin{array}{l}\text { MDA } \downarrow \text {, GSH } \uparrow, \text { SOD } \uparrow \text {; lung W/D ratio } \downarrow ; H \& E \uparrow ; I L-I \beta, T N F-\alpha \downarrow \text {; } \\
\text { NF- } \mathrm{B} \downarrow \downarrow\end{array}$ & [42] \\
\hline $\begin{array}{l}\mathrm{Se} @ \mathrm{SiO}_{2} \mathrm{PVP} \\
\text { coated }\end{array}$ & $\sim 55$ & $\begin{array}{l}100 \mu g / \mathrm{kg} \text { (i.n. I } \\
\text { h pre) }\end{array}$ & $\begin{array}{l}\text { Male C57BL/6 } \\
\text { mice LPS (i.n.) }\end{array}$ & $\begin{array}{l}\text { Total cell } \downarrow \text {, neutrophil } \downarrow \text {, macrophage } \uparrow \text {; IL-I } \beta, \text { CCL-2, IL- } 6 \downarrow \text {; total } \\
\text { protein, lung W/D ratio } \downarrow ; \text { H\&E } \uparrow \text {, score } \downarrow\end{array}$ & [36] \\
\hline
\end{tabular}

a positive charge and membrane-penetrating properties were suitable for gene delivery. The siS1PLyase/ HMGB1A/R3V6 delivering a siRNA ternary complex, in which siS1PLyase down-regulates the S1PLyase (sphingosine-1-phosphate lyase) and S1P on alveolar macrophages to block the NF- $\mathrm{BB}$ signaling pathway, demonstrated synergistic anti-inflammatory effects. ${ }^{68}$ Self-assembling peptide EAK16-II carrying Src tyrosine kinase inhibitor (PP2) demonstrated a lower toxicity, and a satisfactory anti-inflammatory effect against the lung ischemia-reperfusion (IR) model in rats. ${ }^{34}$ Recently, a self-assemble DNA origami nanorobotic delivery platform is available with nanoscale precision sensing, movement and manipulation properties, which may provide a new strategy for nanomedicine-based gene therapy. ${ }^{111,112}$

\section{Inorganic Nanomedicine}

Inorganic nanomedicines are generally composed of inert and biocompatible metals, which endow them with stable characteristics and smaller diameters. Most inorganic nanomedicines are highly efficient and exabit multiple effects during biological applications. Gold, cerium dioxide $\left(\mathrm{CeO}_{2}\right)$ and selenium (Se) have been used to treat ALI. The biggest challenge that limits their application is their elimination from the body, as repeated administration can result in toxicity by accumulation effects. ${ }^{101}$ The strategies to tackle this problem include biogenic route of synthesis, conjugating peptides on metallic nanoparticles or immobilizing inorganic nanoparticles on silica nanoparticles. The main mechanisms of inorganic nanomedicine to treat ALI include inhibiting the inflammatory $\operatorname{signal}^{37-41,44}$ and scavenging oxidants ${ }^{36,42,43}$ (Table 4).

Gold nanoparticles (GNPs) could reduce the acute inflammatory response and excessive ROS production, protecting lung tissue from LPS-induced morphological changes. ${ }^{38}$ However, they tend to be trapped in the liver and spleen and are nonbiodegradable; so, the biosafety concerns still exist. The biogenic route of GNPs synthesis offers an efficient way to tackle the biosafety problems, which can fabricate spherical, ${ }^{113}$ anisotropic, and high aspect ratio gold nanomaterials. ${ }^{114}$ The molecular dynamic simulation, supported with experimental photothermal therapy, has shown the excellent application of these GNPs in nanomedicine for clearing biofilm and promoting the grown of fibroblast. ${ }^{115,116}$ These biomineralized nanomaterials proved excellent imaging agents ${ }^{117}$ and are drug carriers with enhanced bioavailability in vitro ${ }^{118}$ and in vivo. ${ }^{119}$

Modifying the GNPs with peptides is another way to enhance efficiency and safety. Peptide-modified GNPs could modulate the process of endosomal acidification and inhibit multiple Toll-like receptor (TLR) 
A

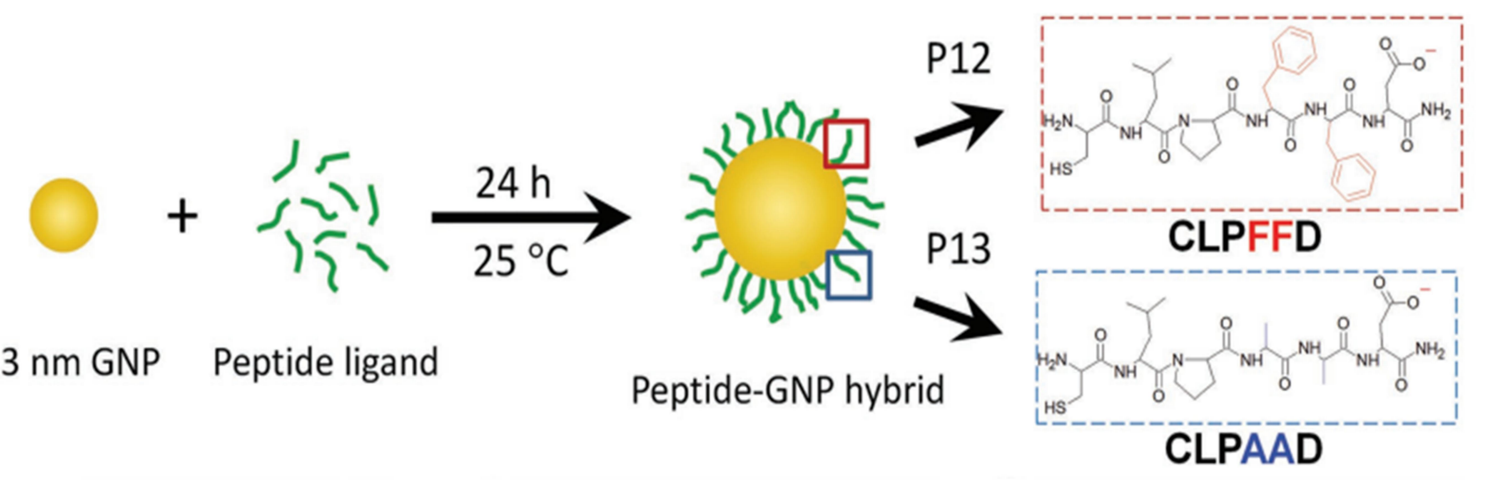

B

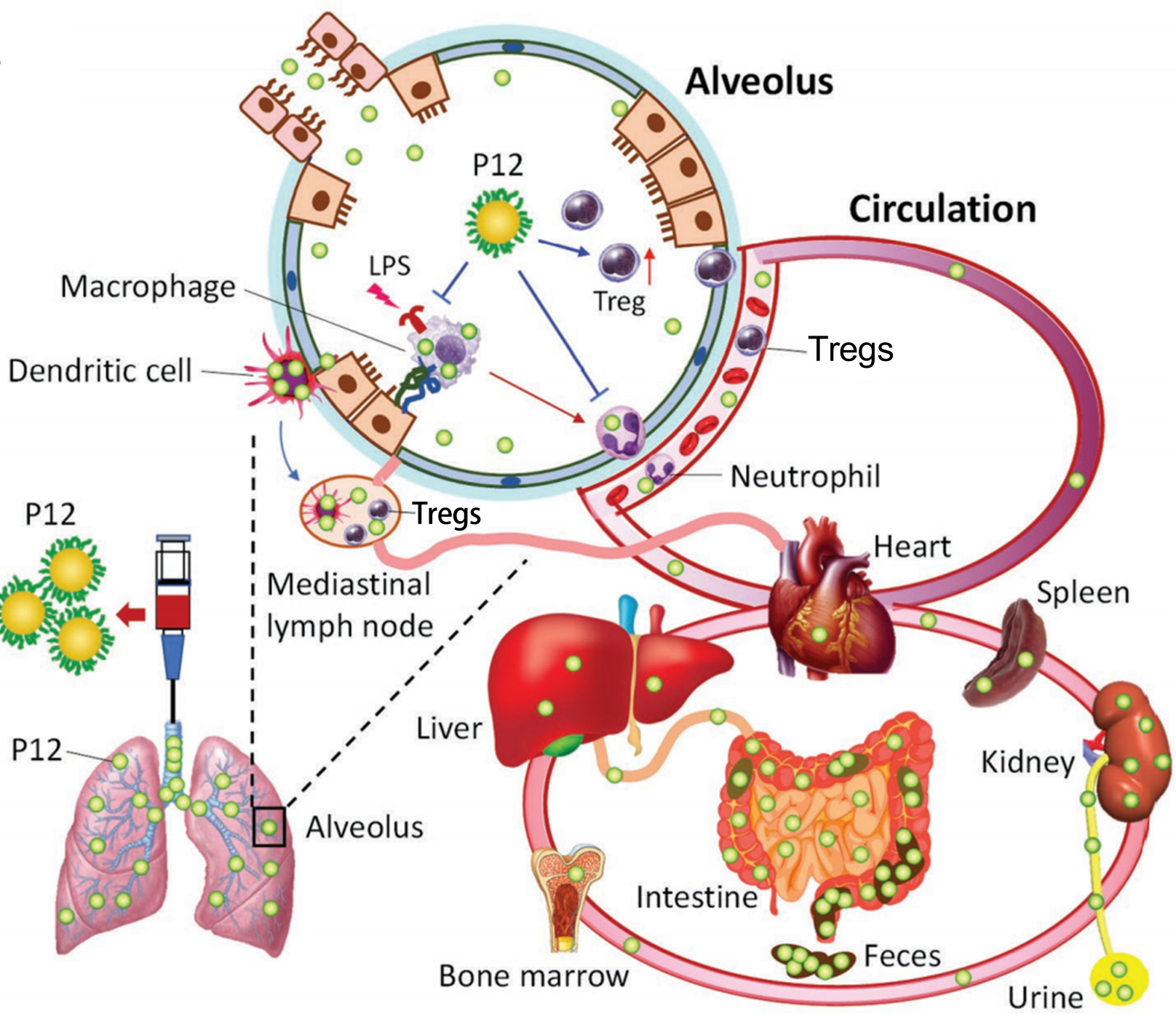

Figure 4 Inorganic nanomedicine. (A) Peptide-gold nanoparticle hybrids. (B) The nanoparticles effectively reduced lung injury and were effectively excreted at 26 h postadministration.

Notes: Reproduced with the permission from Xiong Y, Gao W, Xia F et al. Peptide-Gold Nanoparticle Hybrids as Promising Anti-Inflammatory Nanotherapeutics for Acute Lung Injury: In Vivo Efficacy, Biodistribution, and Clearance. Adv Healthc Mater. 2018;7(19):el8005I0. @ 20I8 WILEY-VCH Verlag GmbH \& Co. KGaA, Weinheim. ${ }^{4 I}$

signaling pathways in macrophages. ${ }^{120} \mathrm{~A}$ unique class of hybrid GNPs (P12) was designed, which was made of a $13 \mathrm{~nm}$ GNP core and a hexapeptide (CLPFFD) surface coating. P12 showed therapeutic effects by targeting the macrophages and increasing the regulatory $\mathrm{T}$ cells (Tregs). When administrated 
A

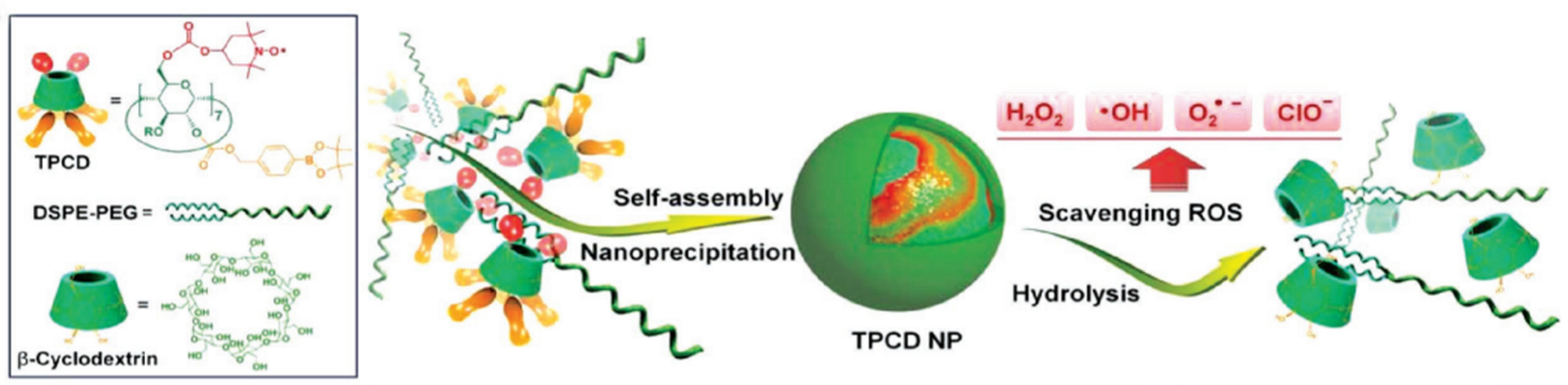

B

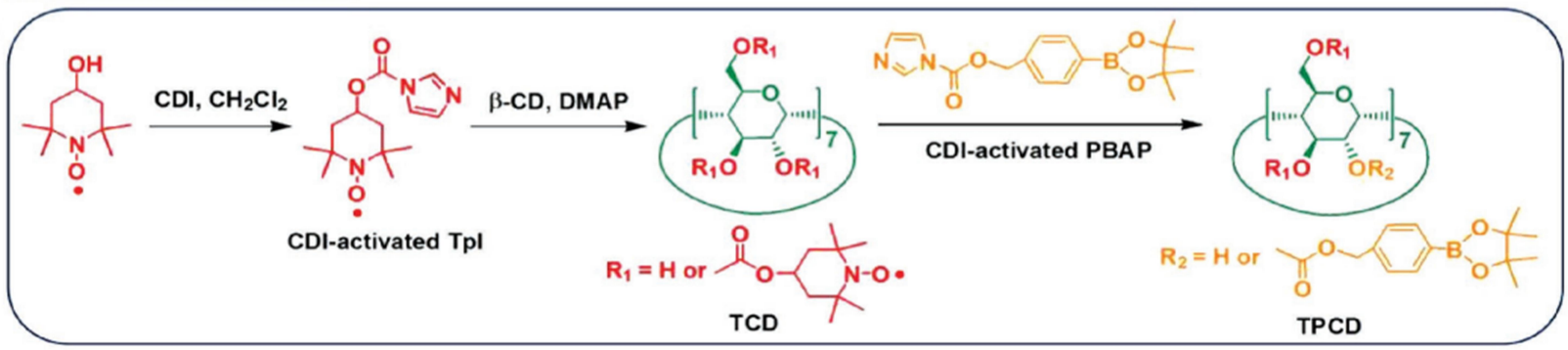

C

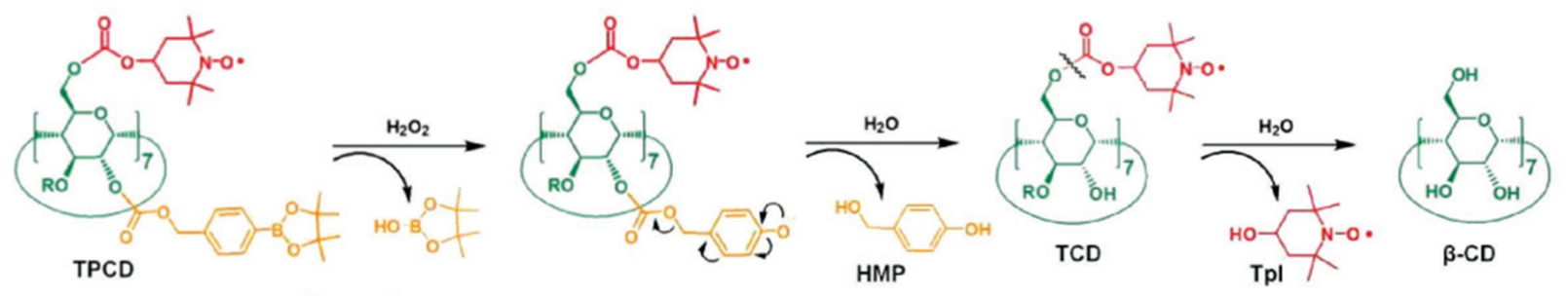

Figure 5 A superoxidase dismutase/catalase mimetic material based on functionalized $\beta$-cyclodextrin ( $\beta$-CD) eliminated a broad spectrum of ROS. (A) Schematic illustration of material and nanoparticle. (B) The synthetic route of $\beta-C D$ conjugated with Tempol (Tpl) and PBAP units (TPCD). (C) The mechanism for the $\mathrm{H}_{2} \mathrm{O}_{2}$-mediated hydrolysis of TPCD.

Notes: Reproduced with the permission from Li L, Guo J, Wang Y et al. A Broad-Spectrum ROS-Eliminating Material for Prevention of Inflammation and Drug-Induced Organ Toxicity. Adv Sci (Weinh). 2018;5(I0):180078I. (c) 2018 The Authors. Published by WILEY-VCH Verlag GmbH \& Co. KGaA, Weinheim under Creative Commons Attribution 4.0 International License. ${ }^{47}$

intratracheally, only approximately $8.49 \% \pm 0.7 \%$ of the injected dose remained in all the tested organs/ tissues. At both 6 and $26 \mathrm{~h}$ post-intratracheal injection, a significant amount of P12 was detected in the feces and the amount in the intestine was much higher than that in the liver, suggesting that P12 was cleared through a hepatobiliary route ${ }^{41}$ (Figure 4). Furthermore, the 20-nm hybrid P12 (G20) was more potent than the 13-nm hybrid P12 (G13) and 5-nm hybrid P12 (G5) in inhibiting TLR4 activation and its downstream cytokine production. The P12 (G20) exhibited a higher cellular uptake and a stronger endosomal $\mathrm{pH}$ buffering capacity, endowing it with enhanced inhibitory effects. ${ }^{39}$ Cigarette smoke extract (CSE, 1\%) was able to be adsorbed onto the GNP hybrids and largely increased their cellular uptake. CSE-P12 inhibited TLR4 activation through endosomal acidification and contributed to autophagy induction and subsequent antioxidant protein expression. ${ }^{40}$ P12 could also increase the alveolar anti-inflammatory M2 phenotype macrophages by polarization in the BALF and lung tissues, and decrease M1 macrophages in the alveolar and interstitial spaces. ${ }^{37}$

$\mathrm{CeO}_{2}$ is a promising oxidant-scavenging nanoparticle, but its slow elimination induces concern for its toxic effect. By immobilizing it on the surface of silica, the toxicity of the cerium nanoparticles was reduced. The $\mathrm{CeO}_{2}$ nanoparticles showed anti-inflammatory and antioxidant effects, as well as stimulating oxygen consumption in healthy rats and those with pneumonia. ${ }^{43}$ The same strategy was adopted to fabricate porous $\mathrm{Se} @ \mathrm{SiO}_{2}$ PVP coated nano-spheres. In a paraquat-induced rat model, the nano-spheres could attenuate oxidative stress, eliminate ROS, and reduce inflammatory cytokines. ${ }^{42}$ The nano- 
Table 5 Other Nanomedicine

\begin{tabular}{|c|c|c|c|c|c|c|}
\hline Material (Moiety) & $\begin{array}{l}\text { Drug/ } \\
\text { Gene }\end{array}$ & $\begin{array}{l}\text { Size } \\
(\mathrm{nm})\end{array}$ & Dose (Route) & $\begin{array}{l}\text { Animal } \\
\text { Model } \\
\text { (Route) }\end{array}$ & In vivo Therapeutic Outcomes & Ref. \\
\hline Polydopamine & & $\sim 80$ & $\begin{array}{l}10 \mathrm{mg} / \mathrm{kg} \text { (i.n. } \\
30 \mathrm{~min} \text { post) }\end{array}$ & $\begin{array}{l}\text { Female BALB/c } \\
\text { mice LPS (i.n.) }\end{array}$ & $\begin{array}{l}\text { IL-6, TNF- } \alpha, \text { CXCL-2, MPO, protein, } \\
\text { leukocyte, neutrophil } \downarrow ; \text { H\&E } \uparrow\end{array}$ & [46] \\
\hline $\begin{array}{l}\beta \text {-cyclodextrin (Tempol } \\
\& \text { PBAP) }\end{array}$ & & $109 \pm 2$ & $\begin{array}{l}0.1 \text { or } 1.0 \mathrm{mg} / \mathrm{kg} \\
\text { (i.v. I h post) }\end{array}$ & $\begin{array}{l}\text { Male BALB/c } \\
\text { mice LPS (i.t.) }\end{array}$ & $\begin{array}{l}\text { Lung W/D ratio, TNF- } \alpha, \mathrm{IL}-\mathrm{I} \beta, \mathrm{H}_{2} \mathrm{O}_{2} \text {, MPO, } \\
\text { neutrophil } \downarrow ; \mathrm{H} \& \mathrm{E} \uparrow\end{array}$ & [47] \\
\hline $\begin{array}{l}\beta \text {-cyclodextrin } \\
\text { (Luminol) }\end{array}$ & & $\begin{array}{l}238 \pm \\
26\end{array}$ & $\begin{array}{l}100 \mathrm{mg} / \mathrm{kg} \text { (i.v. I } \\
\text { h post) }\end{array}$ & $\begin{array}{l}\text { Male BALB/c } \\
\text { mice LPS (i.t.) }\end{array}$ & $\begin{array}{l}\text { TNF- } \alpha \text {, IL-I } \beta \text {, lung W/D ratio, lung } \\
\text { permeability } \downarrow ; H \& E \uparrow\end{array}$ & {$[45]$} \\
\hline Bovine serum albumin & Piceatannol & $\begin{array}{l}100 \pm \\
10\end{array}$ & $\begin{array}{l}4.3 \mathrm{mg} / \mathrm{kg} \text { (i.v. } 2 \\
\text { h post) }\end{array}$ & $\begin{array}{l}\text { Male CDI mice } \\
\text { LPS (i.p.) }\end{array}$ & MPO, neutrophil, leukocyte $\downarrow$ & {$[58]$} \\
\hline Bovine serum albumin & TPCA-I & $\sim 140$ & $\begin{array}{l}8 \mathrm{mg} / \mathrm{kg} \text { (i.v. } 4 \\
\text { h post) }\end{array}$ & $\begin{array}{l}\text { Adult CDI mic } \\
\text { LPS (i.t.) }\end{array}$ & Leukocyte \& neutrophil, IL-6, TNF- $\alpha$, protein $\downarrow$ & [57] \\
\hline $\begin{array}{l}\text { Extracellular } \\
\text { nanovesicles (ICAM-I } \\
\text { antibody) }\end{array}$ & TPCA-I & 200 & $\begin{array}{l}0.33 \text { or } \mathrm{I} \mathrm{mg} / \mathrm{kg} \\
\text { (i.v. } 3 \mathrm{~h} \text { post) }\end{array}$ & $\begin{array}{l}\text { Adult CDI } \\
\text { mice LPS (i.t.) }\end{array}$ & Neutrophil, protein, TNF- $\alpha$, IL-6 $\downarrow$ & {$[56]$} \\
\hline $\begin{array}{l}\text { Extracellular } \\
\text { nanovesicles }\end{array}$ & Piceatannol & $\sim 260$ & $\begin{array}{l}2 \mathrm{mg} / \mathrm{kg} \text { (i.v. } 2 \\
\text { h post) }\end{array}$ & $\begin{array}{l}\text { Adult CDI } \\
\text { mice LPS (i.t.) }\end{array}$ & Neutrophil, leukocyte, TNF- $\alpha$, IL-6, protein $\downarrow$ & {$[54]$} \\
\hline PEVs & TPCA-I & $100-150$ & $\begin{array}{l}\text { I mg/kg (i.v. } 4 \\
\text { h post) }\end{array}$ & $\begin{array}{l}\text { Female BALB/c } \\
\text { mice LPS (i.t.) }\end{array}$ & $\begin{array}{l}\text { TNF- } \alpha \text {, IL-6, IL-I } \beta \text {, macrophages, T cells, } \\
\text { ROS } \downarrow ; \text { MPO, MDA, wet/dry ration } \downarrow ; \text { H\&E }\end{array}$ & [79] \\
\hline
\end{tabular}

spheres could also modulate mitochondrial function, activity, and dynamics, significantly increasing the epithelial cells' resistance to oxidative injury. ${ }^{36}$

\section{Other Nanomedicine}

Polydopamine is a natural biopolymer that can selfassemble or be a film coating. Enriched phenol groups enable it to act as a nano-enzyme to scavenge $\mathrm{H}_{2} \mathrm{O}_{2}$ directly or to catalyze the decomposition of $\mathrm{H}_{2} \mathrm{O}_{2}$. Polydopamine alleviated lung tissue damage by diminishing ROS generation. ${ }^{46} \beta$-cyclodextrin $(\beta-C D)$ is a cyclic oligosaccharide that mimics enzyme conformation with a hydrophilic rim and a hydrophobic cavity. Two ROS eliminating agents, Tempol and PBAP, were simultaneously conjugated to $\beta-\mathrm{CD}$ to construct a superoxidase dismutase/catalase mimetic material (TPCD). TPCD nanoparticles eliminated a broad spectrum of ROS, protected macrophages from apoptosis, attenuated inflammatory responses and oxidative stress ${ }^{47}$ (Figure 5). In another study, luminol-conjugating $\beta$-CD (LCD) nanoparticles could act on both neutrophils and macrophages, effectively inhibiting the inflammatory response, oxidative stress and cell migration, demonstrating desirable efficacy in treating ALI with biosafety ${ }^{45}$ (Table 5).

Inflamed vasculature targeting ability was achieved by conjugating anti-ICAM-1 antibody or peptides to nanoparticles. $^{121}$ However, this strategy might impair their specificity and affinity, especially when administrated in vivo. ${ }^{122}$ During inflammation, neutrophils abundantly express integrin $\beta 2$; this integrin interacts with the ICAM1 molecules on the endothelial cells. ${ }^{123}$ This interaction could be blocked to inhibit the accumulation of neutrophils, or use this interaction for targeting drug delivery. Piceatannol blocks the "outside-in" integrin signaling in neutrophils. Albumin nanoparticles loading piceatannol were taken up by neutrophils, detaching neutrophils' adherence and eliciting their release into the circulation. ${ }^{58}$ Inspired by the study above, it is promising to design nanoparticles that hitchhike activated neutrophils in situ; then, neutrophils could deliver nanoparticles to the inflammatory site by adhering and migrating across the blood vessel endothelium into the inflammatory tissues. Using bovine serum albumin to deliver TPCA-1, this nanoparticle dramatically ameliorated inflammation and decreased permeability in the lung. ${ }^{57}$ Nitrogen cavitation 


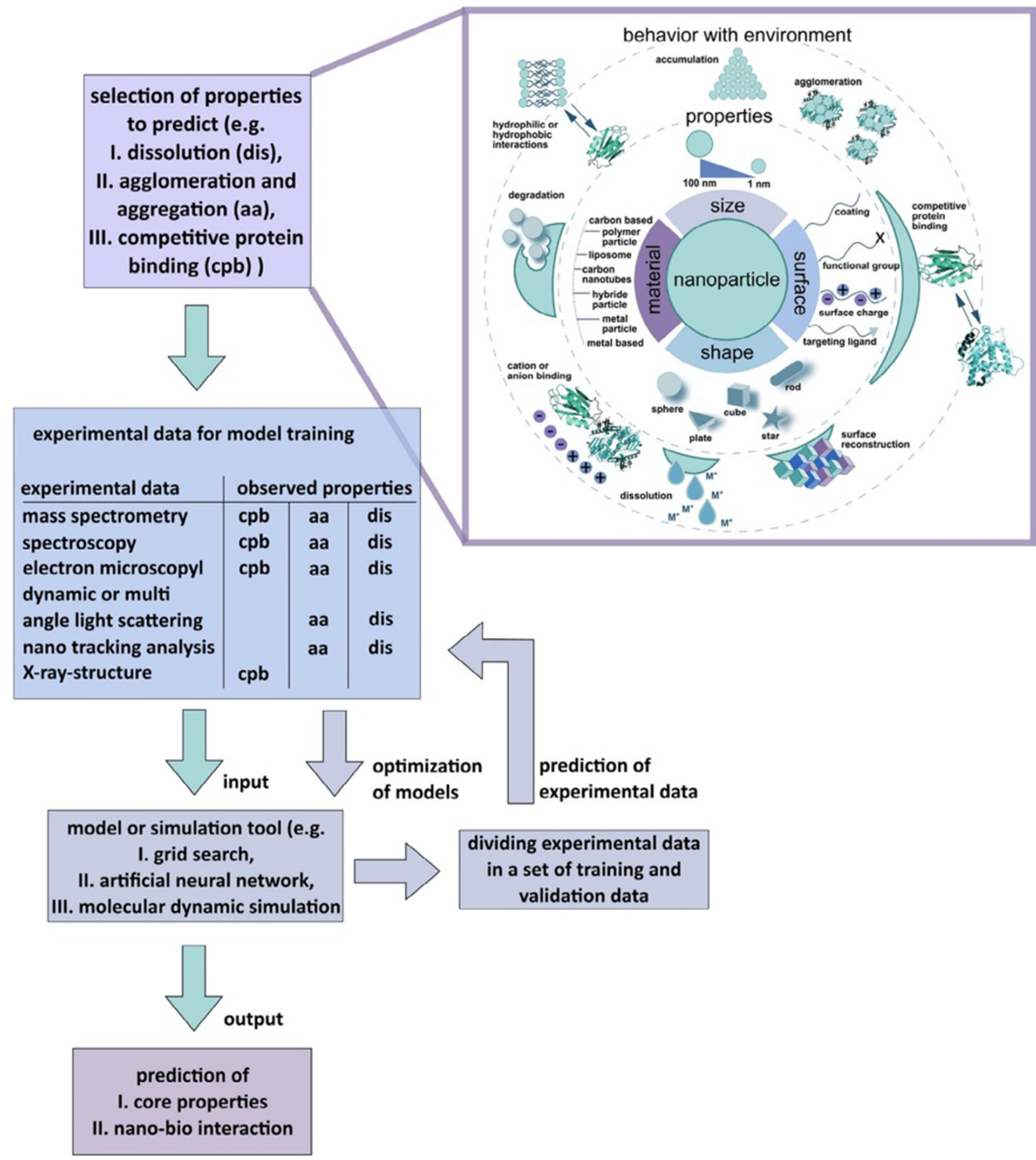

Figure $6 \mathrm{Al}$ toolbox for understanding bio-physicochemical identity at the nano-bio interface.

Notes: Reproduced with the permission from Singh AV, Rosenkranz D, Ansari MHD et al. Artificial Intelligence and Machine Learning Empower Advanced Biomedical Material Design to Toxicity Prediction. Advanced Intelligent Systems. 2020;2(I2). (C 2020 The Authors. Published by Wiley-VCH GmbH under Creative Commons Attribution 4.0 International License. ${ }^{125}$

was initially employed to isolate neutrophil plasma membrane as sealed vesicles, which minimizes lysosomal and nuclear rupture. Neutrophils were placed in the cell disruption bomb with optimum pressure and duration of equilibration, then the pressure was quickly released to disrupt cells, and the vesicles were obtained followed by a series of centrifuge. ${ }^{124}$ The cell membrane nanovesicles, which are made from activated neutrophils using nitrogen 
cavitation, possess intact targeting molecules of integrin $\beta 2$, and can selectively bind to inflamed vasculature. Human neutrophils are abundant in the blood; thus, this strategy could be utilized to develop personalized nanomedicines. ${ }^{56}$ In another study, piceatannol was remotely loaded in nitrogen cavitation nanovesicles via a $\mathrm{pH}$ gradient. The piceatannol-loading nanovesicles dramatically alleviated ALI and sepsis induced by LPS. ${ }^{54}$

Platelet-derived extracellular vesicles (PEVs) are another cell-based drug-delivery system. The platelets intrinsically have inflammation-site affinity and are suitable for targeting ALI treatment. When loaded with TPCA1 , they significantly inhibited pulmonary inflammatory cell infiltration and calmed regional cytokine storm syndromes. This system is also suitable for the treatment of chronic atherosclerotic plaque, rheumatoid arthritis, and wounds associated with the skin. ${ }^{79}$

\section{Conclusion and Perspective}

To date, no pharmacological therapy has been proved to be completely effective in treating ALI. Although many therapies have been proved to be effective in experiments, clinical translation is small. The advent of nanomedicine could open new avenues to address current limitations in the field of traditional pharmacological therapies, but challenges still remain to improve their clinical translatability.

The toxicity and safety concerns are great challenges for nanomedicine clinical translation. Recent advances in machine learning and artificial intelligence immensely decoded and empowered the cell-nanomaterial interaction, which gifted the computational tool for the prediction process ${ }^{125,126}$ and in-silico methods ${ }^{127,128}$ to potentially decipher the quantitative nanostructure activity-relationship (Nano-QSAR) for nanotoxicology and nanotherapeutics (Figure 6).

Similar to the enhanced permeability and retention (EPR) effect in a solid tumor, the inflammation-specific retention is called ELVIS. ${ }^{18}$ The role of EPR in the cancer barrier is somewhat oversold considering that less than $5 \%$ of nanomedicine formulations accumulate at the site of tumor; ${ }^{129}$ and the heterogeneous outcomes of clinical trials of nanomedicine can be explained by the inter- and intraindividual heterogeneity in EPR-mediated targeting. Biological nanomedicine which employs bacterial, ${ }^{100,130,131}$ human cells and tissue ${ }^{59,132}$ and
DNAs ${ }^{111}$ as carriers seems promising ways to improve and individualize nanomedicine treatments.

A future direction to improve nanomedicine clinical translatability is about to integrate nanomedicines and/ or nanorobots with biological cells, which do not need sophisticated instruments, space, chemicals, acoustic and magnetic setup to deliver agents inside the body. ${ }^{130-133}$ Bacteria-driven microparticle swimmers possess actuation and sensing capabilities, which make them promising active carriers with high efficiency of tissue cells. ${ }^{100,130,131}$ Sperm cell-driven microrobots are biocompatible microrobots, which are fast microswimmers in stagnant fluids without the need for toxic media or fuel, might have an impact on the development of assisted reproductive technologies. ${ }^{132}$ These emerging strategies are a promising way to realize personalized pharmacological therapy.

The increasing use of nanodiagnostics and nanomedicine for personalized and targeting therapy raises potential social and ethical conundrums. Nanomedicine commercialization requires a large investment, ${ }^{134}$ and the cost-effective benefit is an inevitable issue. ${ }^{135}$ Extreme profitability concept leads to concerns that global equality in access to health care might be even further compromised. Continuous efforts to cultivate cost-effective nanomedicine with more security are mandatory to make better use of nanotechnologies for global welfare.

\section{Abbreviations}

Symbols: "^", increase or improve; " $\downarrow$ ", decrease or deteriorate; “-”, no significant difference; NG, not given; pre, before stimulation; post, after stimulation; Administrations: i.g, intra gastric; i.n, intranasal; inh, inhalation; i.p, intraperitoneal; i.t, intratracheal; i.v, intravenous; p.o, per os; Others: ACE, angiotensin-converting enzyme; AKP, alkaline phosphatase; ALI, acute lung injury; ARDS, acute respiratory distress syndrome; CAT, catalase; Chol, cholesterol; CINC-1, cytokine induced neutrophil chemoattractan; CoV, coronavirus; COVID-19, coronavirus disease 2019; DCFH, 2.7-dichloro dihydro-fluoresce indiacetate; DiD, 1.1'-Dioctadecyl-3,3,3',3'-Tetramethylindodicarbocyanine, 4-Chlorobenzenesulfonate Salt; DiR, 1.1'-dioctadecyl $-3,3,3^{\prime}, 3^{\prime}$-tetramethylindotricarbocyanine iodide; DOPC, 1.2-dioleoyl-sn-glycero-3-phosphocholine; DOTMA, N [1-(2,3-dioleyloxy) propyl]-N,N,N-trimethylammonium chloride; DPPC, 1.2-dipalmitoyl-snglycero-3-phosphocholine; DSPC, 1.2-distearoyl-sn-glycero-3-phosphocholine; 
DSPE-PEG, distearylphosphatidylethanolamine-polyethylene glycol; EUK-134, chloro[[2,2'-[1,2-ethanediylbis [(nitrilo- $\kappa \mathrm{N})$ methylidyne]] bis[6-methoxyphenolato- $\kappa \mathrm{O}]]$ manganese; Fuc, fucosylated; GSH, glutathione; HEMA, hydroxyethyl methacrylate; HMGB1A, high mobility group box 1 antibody; HYP, hydroxyproline; KC, keratinocyte-derived chemokine; LPS, lipopolysaccharide; Man, mannosylated; MCT, medium-chain triglycerides; MDA, malondialdehyde; MIP, macrophage inflammatory protein; MPB, 1.2-dioleoyl-sn-glycero-3-phosphoethanolamine-N[4-(p-maleimidophenyl)butyramide] sodium salt; MPO, myeloperoxidase; NETs, neutrophil extracellular traps; PBAP, phenylboronic acid pinacol ester; PC, phosphatidylcholine; PEG, polyethylene glycol; PG, L- $\alpha$ phosphatidylglycerol; PVP, polyvinylpyrrolidone; RAGE, advanced glycation end products; SARS, severe acute respiratory syndrome; siRNA, small interfering RNA; SOD, superoxide dismutase; SPC, soy phosphatidylcholine; SPION, superparamagnetic iron oxide nanoparticles; TMAEMA, [2-(methacryloyloxy)-ethyl] trimethylammonium chloride; TPCA-1, 2-[(Aminocarbonyl)amino]5-(4-fluorophenyl)-3-thiophenecarboxamide; W/D ratio, wet-to-dry ratio; V`E, calculated minute ventilation; $\mathrm{V}^{\prime} \mathrm{O} 2$, rate of oxygen uptake per minute; VT, tidal volume.

\section{Acknowledgments}

This work was financially supported by the National Natural Science Foundation of China (51773196, 51803072 and 51573184), the Jilin Provincial Science and Technology Development Program (20180520207JH), and the Bethune Plan Research Project of Jilin University (2018B15).

\section{Disclosure}

The authors report no conflicts of interest in this work.

\section{References}

1. Fan E, Brodie D, Slutsky AS. Acute respiratory distress syndrome: advances in diagnosis and treatment. JAMA. 2018;319(7):698-710. doi:10.1001/jama.2017.21907

2. Matthay MA, Zemans RL, Zimmerman GA, et al. Acute respiratory distress syndrome. Nat Rev Dis Primers. 2019;5(1):18.

3. Grasselli G, Tonetti T, Protti A, et al. Pathophysiology of COVID-19associated acute respiratory distress syndrome: a multicentre prospective observational study. Lancet Respir Med. 2020;8(12):1201-1208. doi:10.1016/S2213-2600(20)30370-2

4. Matthay MA, Ware LB, Zimmerman GA. The acute respiratory distress syndrome. J Clin Invest. 2012;122(8):2731-2740. doi:10.1172/ JCI60331

5. Matthay MA, Zemans RL. The acute respiratory distress syndrome: pathogenesis and treatment. Annu Rev Pathol. 2011;6(1):147-163. doi:10.1146/annurev-pathol-011110-130158
6. Thompson BT, Chambers RC, Liu KD. Acute respiratory distress syndrome. N Engl J Med. 2017;377(6):562-572. doi:10.1056/ NEJMra1608077

7. Villar J, Ferrando C, Martínez D, et al. Dexamethasone treatment for the acute respiratory distress syndrome: a multicentre, randomised controlled trial. Lancet Respir Med. 2020;8(3):267-276. doi:10.1016/S2213-2600(19)30417-5

8. Steinberg KP, Hudson LD, Goodman RB, et al. Efficacy and safety of corticosteroids for persistent acute respiratory distress syndrome. N Engl J Med. 2006;354(16):1671-1684.

9. Zeiher BG, Artigas A, Vincent J-L, et al. Neutrophil elastase inhibition in acute lung injury: results of the STRIVE study. Crit Care Med. 2004;32(8):1695-1702. doi:10.1097/01. CCM.0000133332.48386.85

10. Altintas ND, Atilla P, Iskit AB, Topeli A. Long-term simvastatin attenuates lung injury and oxidative stress in murine acute lung injury models induced by oleic Acid and endotoxin. Respir Care. 2011;56(8):1156-1163. doi:10.4187/respcare.00770

11. McAuley DF, Laffey JG, O'Kane CM, et al. Simvastatin in the acute respiratory distress syndrome. $N$ Engl J Med. 2014;371 (18):1695-1703. doi:10.1056/NEJMoa1403285

12. Griffiths MJD, Evans TW. Inhaled nitric oxide therapy in adults. $N$ Engl J Med. 2005;353(25):2683-2695. doi:10.1056/ NEJMra051884

13. Jagrosse ML, Dean DA, Rahman A, Nilsson BL. RNAi therapeutic strategies for acute respiratory distress syndrome. Transl Res. 2019;214:30-49.

14. Boyle AJ, Sweeney RM, McAuley DF. Pharmacological treatments in ARDS; a state-of-the-art update. BMC Med. 2013;11 (1):166. doi:10.1186/1741-7015-11-166

15. Lammers T, Sofias AM, van der Meel R, et al. Dexamethasone nanomedicines for COVID-19. Nat Nanotechnol. 2020;15 (8):622-624. doi:10.1038/s41565-020-0752-Z

16. Zhang $\mathrm{P}$, Zhang $\mathrm{Y}$, Ding $\mathrm{X}$, et al. A multistage cooperative nanoplatform enables intracellular co-delivery of proteins and chemotherapeutics for cancer therapy. Adv Mater. 2020;32(46): e2000013. doi:10.1002/adma.202000013

17. Li J, Jia Y, Zhang P, et al. Celastrol Self-Stabilized Nanoparticles for Effective Treatment of Melanoma. Int $J$ Nanomedicine. 2020;15:1205-1214. doi:10.2147/IJN.S232603

18. d'Arcy R, Tirelli N. Fishing for fire: strategies for biological targeting and criteria for material design in anti-inflammatory therapies. Polym Adv Technol. 2014;25(5):478-498.

19. de Oliveira MTP. de Sa Coutinho D, Tenorio de Souza E, et al. Orally delivered resveratrol-loaded lipid-core nanocapsules ameliorate LPS-induced acute lung injury via the ERK and PI3K/Akt pathways. Int J Nanomedicine. 2019;14:5215-5228. doi:10.2147/ IJN.S200666

20. Li S, Chen L, Wang G, et al. Anti-ICAM-1 antibody-modified nanostructured lipid carriers: a pulmonary vascular endothelium-targeted device for acute lung injury therapy. $J$ Nanobiotechnology. 2018;16 (1):105. doi:10.1186/s12951-018-0431-5

21. Li SJ, Wang XJ, Hu JB, et al. Targeting delivery of simvastatin using ICAM-1 antibody-conjugated nanostructured lipid carriers for acute lung injury therapy. Drug Deliv. 2017;24(1):402-413. doi:10.1080/10717544.2016.1259369

22. Li N, Weng D, Wang SM, et al. Surfactant protein-A nanobody-conjugated liposomes loaded with methylprednisolone increase lung-targeting specificity and therapeutic effect for acute lung injury. Drug Deliv. 2017;24(1):1770-1781. doi:10.1080/ 10717544.2017.1402217

23. D'Almeida APL. Pacheco de Oliveira MT, de Souza ET, et al. alpha-bisabolol-loaded lipid-core nanocapsules reduce lipopolysaccharide-induced pulmonary inflammation in mice. Int J Nanomedicine. 2017;12:4479-4491. doi:10.2147/IJN.S130798 
24. Chen XY, Wang SM, Li N, et al. Creation of lung-targeted dexamethasone immunoliposome and its therapeutic effect on bleomycin-induced lung injury in rats. PLoS One. 2013;8(3): e58275. doi:10.1371/journal.pone.0058275

25. Wijagkanalan W, Higuchi Y, Kawakami S, Teshima M, Sasaki H, Hashida M. Enhanced anti-inflammation of inhaled dexamethasone palmitate using mannosylated liposomes in an endotoxin-induced lung inflammation model. Mol Pharmacol. 2008;74(5):1183-1192. doi:10.1124/mol.108.050153

26. Suntres ZE, Shek PN. Prophylaxis against lipopolysaccharide-induced lung injuries by liposome-entrapped dexamethasone in rats. Biochem Pharmacol. 2000;59 (9):1155-1161. doi:10.1016/S0006-2952(99)00411-6

27. Suntres ZE, Shek PN. Alleviation of paraquat-induced lung injury by pretreatment with bifunctional liposomes containing alpha-tocopherol and glutathione. Biochem Pharmacol. 1996;52 (10):1515-1520. doi:10.1016/S0006-2952(96)89626-2

28. Zhang CY, Lin W, Gao J, et al. pH-Responsive Nanoparticles Targeted to Lungs for Improved Therapy of Acute Lung Inflammation/Injury. ACS Appl Mater Interfaces. 2019;11 (18):16380-16390. doi:10.1021/acsami.9b04051

29. Jin F, Liu D, Yu H, et al. Sialic Acid-Functionalized PEG-PLGA Microspheres Loading Mitochondrial-Targeting-Modified Curcumin for Acute Lung Injury Therapy. Mol Pharm. 2019;16 (1):71-85. doi:10.1021/acs.molpharmaceut.8b00861

30. Jurek SC, Hirano-Kobayashi M, Chiang H, Kohane DS, Matthews BD. Prevention of ventilator-induced lung edema by inhalation of nanoparticles releasing ruthenium red. Am J Respir Cell Mol Biol. 2014;50(6):1107-1117. doi:10.1165/rcmb.2013$0163 \mathrm{OC}$

31. Lin EH, Chang HY, Yeh SD, Yang KY, Hu HS, Wu CW. Polyethyleneimine and DNA nanoparticles-based gene therapy for acute lung injury. Nanomedicine. 2013;9(8):1293-1303. doi:10.1016/j.nano.2013.05.004

32. Park JH, Kim HA, Park JH, Lee M. Amphiphilic peptide carrier for the combined delivery of curcumin and plasmid DNA into the lungs. Biomaterials. 2012;33(27):6542-6550. doi:10.1016/j. biomaterials.2012.05.046

33. Kim HA, Park JH, Lee S, et al. Combined delivery of dexamethasone and plasmid DNA in an animal model of LPS-induced acute lung injury. J Control Release. 2011;156(1):60-69. doi:10.1016/j. jconrel.2011.06.041

34. Fung SY, Oyaizu T, Yang H, et al. The potential of nanoscale combinations of self-assembling peptides and amino acids of the Src tyrosine kinase inhibitor in acute lung injury therapy. Biomaterials. 2011;32(16):4000-4008. doi:10.1016/j. biomaterials.2011.02.005

35. Howard MD, Greineder CF, Hood ED, Muzykantov VR. Endothelial targeting of liposomes encapsulating SOD/catalase mimetic EUK-134 alleviates acute pulmonary inflammation. J Control Release. 2014;177:34-41. doi:10.1016/j. jconrel.2013.12.035

36. Wang M, Wang K, Deng G, et al. Mitochondria-modulating Porous Se@SiO2 Nanoparticles Provide Resistance to Oxidative Injury in Airway Epithelial Cells: implications for Acute Lung Injury. Int J Nanomedicine. 2020;15:2287-2302. doi:10.2147/ IJN.S240301

37. Wang L, Zhang H, Sun L, et al. Manipulation of macrophage polarization by peptide-coated gold nanoparticles and its protective effects on acute lung injury. $J$ Nanobiotechnology. 2020;18 (1):38. doi:10.1186/s12951-020-00593-7

38. Dos Santos Haupenthal DP, Mendes C, de Bem Silveira G, et al. Effects of treatment with gold nanoparticles in a model of acute pulmonary inflammation induced by lipopolysaccharide. J Biomed Mater Res A. 2020;108(1):103-115. doi:10.1002/jbm. a.36796
39. Gao W, Wang Y, Xiong Y, et al. Size-dependent anti-inflammatory activity of a peptide-gold nanoparticle hybrid in vitro and in a mouse model of acute lung injury. Acta Biomater. 2019;85:203-217. doi:10.1016/j.actbio.2018.12.046

40. Gao W, Wang L, Wang K, et al. Enhanced Anti-inflammatory Activity of Peptide-Gold Nanoparticle Hybrids upon Cigarette Smoke Extract Modification through TLR Inhibition and Autophagy Induction. ACS Appl Mater Interfaces. 2019;11 (36):32706-32719. doi:10.1021/acsami.9b10536

41. Xiong Y, Gao W, Xia F, et al. Peptide-Gold Nanoparticle Hybrids as Promising Anti-Inflammatory Nanotherapeutics for Acute Lung Injury: in Vivo Efficacy, Biodistribution, and Clearance. Adv Healthc Mater. 2018;7(19):e1800510. doi:10.1002/ adhm.201800510

42. Zhu Y, Deng G, Ji A, et al. Porous Se@SiO2 nanospheres treated paraquat-induced acute lung injury by resisting oxidative stress. Int J Nanomedicine. 2017;12:7143-7152. doi:10.2147/IJN.S143192

43. Serebrovska Z, Swanson RJ, Portnichenko V, et al. Antiinflammatory and antioxidant effect of cerium dioxide nanoparticles immobilized on the surface of silica nanoparticles in rat experimental pneumonia. Biomed Pharmacother. 2017;92:69-77. doi:10.1016/j.biopha.2017.05.064

44. Lee D, Zhao J, Yang H, et al. Effective delivery of a rationally designed intracellular peptide drug with gold nanoparticle-peptide hybrids. Nanoscale. 2015;7(29):12356-12360. doi:10.1039/ C5NR02377G

45. Guo J, Li D, Tao H, et al. Cyclodextrin-Derived Intrinsically Bioactive Nanoparticles for Treatment of Acute and Chronic Inflammatory Diseases. Adv Mater. 2019;31(46):e1904607. doi:10.1002/adma.201904607

46. Zhao H, Zeng Z, Liu L, et al. Polydopamine nanoparticles for the treatment of acute inflammation-induced injury. Nanoscale. 2018;10(15):6981-6991. doi:10.1039/C8NR00838H

47. Li L, Guo J, Wang Y, et al. A Broad-Spectrum ROS-Eliminating Material for Prevention of Inflammation and Drug-Induced Organ Toxicity. Adv Sci. 2018;5(10):1800781. doi:10.1002/ advs.201800781

48. Yu HP, Liu FC, Umoro A, et al. Oleic acid-based nanosystems for mitigating acute respiratory distress syndrome in mice through neutrophil suppression: how the particulate size affects therapeutic efficiency. J Nanobiotechnology. 2020;18(1):25.

49. Okeke EB, Louttit C, Fry C, et al. Inhibition of neutrophil elastase prevents neutrophil extracellular trap formation and rescues mice from endotoxic shock. Biomaterials. 2020;238:119836. doi:10.1016/j.biomaterials.2020.119836

50. Liu FC, Yu HP, Lin CY, Elzoghby AO, Hwang TL, Fang JY. Use of cilomilast-loaded phosphatiosomes to suppress neutrophilic inflammation for attenuating acute lung injury: the effect of nanovesicular surface charge. J Nanobiotechnology. 2018;16 (1):35. doi:10.1186/s12951-018-0364-Z

51. Fang CL, Wen CJ, Aljuffali IA, Sung CT, Huang CL, Fang JY. Passive targeting of phosphatiosomes increases rolipram delivery to the lungs for treatment of acute lung injury: an animal study. J Control Release. 2015;213:69-78. doi:10.1016/j.jconrel.2015.06.038

52. Blattes E, Vercellone A, Eutamene H, et al. Mannodendrimers prevent acute lung inflammation by inhibiting neutrophil recruitment. Proc Natl Acad Sci $U$ S A. 2013;110 (22):8795-8800. doi:10.1073/pnas. 1221708110

53. Wang Y, Ding L, Li Z, Chen G, Sun M, Oupicky D. Treatment of acute lung injury and early- and late-stage pulmonary fibrosis with combination emulsion siRNA polyplexes. $J$ Control Release. 2019;314:12-24. doi:10.1016/j.jconrel.2019.10.030

54. Gao J, Wang S, Wang Z. High yield, scalable and remotely drug-loaded neutrophil-derived extracellular vesicles (EVs) for anti-inflammation therapy. Biomaterials. 2017;135:62-73. doi:10.1016/j.biomaterials.2017.05.003 
55. Xu Y, Xiang J, Zhao H, et al. Human amniotic fluid stem cells labeled with up-conversion nanoparticles for imaging-monitored repairing of acute lung injury. Biomaterials. 2016;100:91-100. doi:10.1016/j.biomaterials.2016.05.034

56. Gao J, Chu D, Wang Z. Cell membrane-formed nanovesicles for disease-targeted delivery. J Control Release. 2016;224:208-216. doi:10.1016/j.jconrel.2016.01.024

57. Chu DF, Gao J, Wang ZJ. Neutrophil-Mediated Delivery of Therapeutic Nanoparticles across Blood Vessel Barrier for Treatment of Inflammation and Infection. ACS Nano. 2015;9 (12):11800-11811. doi:10.1021/acsnano.5b05583

58. Wang Z, Li J, Cho J, Malik AB. Prevention of vascular inflammation by nanoparticle targeting of adherent neutrophils. Nat Nanotechnol. 2014;9(3):204-210. doi:10.1038/nnano.2014.17

59. Singh AV, Dad Ansari MH, Dayan CB, et al. Multifunctional magnetic hairbot for untethered osteogenesis, ultrasound contrast imaging and drug delivery. Biomaterials. 2019;219:119394. doi:10.1016/j.biomaterials.2019.119394

60. Jiang S, Li S, Hu J, et al. Combined delivery of angiopoietin-1 gene and simvastatin mediated by anti-intercellular adhesion molecule-1 antibody-conjugated ternary nanoparticles for acute lung injury therapy. Nanomedicine. 2019;15(1):25-36. doi:10.1016/j.nano.2018.08.009

61. Wijagkanalan W, Kawakami S, Higuchi Y, Yamashita F, Hashida M. Intratracheally instilled mannosylated cationic liposome/NFkappaB decoy complexes for effective prevention of LPS-induced lung inflammation. J Control Release. 2011;149 (1):42-50. doi:10.1016/j.jconrel.2009.12.016

62. Ge C, Yang J, Duan S, Liu Y, Meng F, Yin L. Fluorinated alpha-helical polypeptides synchronize mucus permeation and cell penetration toward highly efficient pulmonary siRNA Delivery against Acute Lung Injury. Nano Lett. 2020;20 (3):1738-1746. doi:10.1021/acs.nanolett.9b04957

63. Merckx P, De Backer L, Van Hoecke L, et al. Surfactant protein B (SP-B) enhances the cellular siRNA delivery of proteolipid coated nanogels for inhalation therapy. Acta Biomater. 2018;78:236-246. doi:10.1016/j.actbio.2018.08.012

64. Song JH, Kim JY, Piao C, et al. Delivery of the high-mobility group box 1 box A peptide using heparin in the acute lung injury animal models. J Control Release. 2016;234:33-40. doi:10.1016/ j.jconrel.2016.05.039

65. Ravikumar P, Menon JU, Punnakitikashem P, et al. Nanoparticle facilitated inhalational delivery of erythropoietin receptor cDNA protects against hyperoxic lung injury. Nanomedicine. 2016;12 (3):811-821. doi:10.1016/j.nano.2015.10.004

66. Wu Y, Ma J, Woods PS, et al. Selective targeting of alveolar type II respiratory epithelial cells by anti-surfactant protein-C antibody-conjugated lipoplexes. $J$ Control Release. 2015;203:140-149. doi:10.1016/j.jconrel.2015.02.016

67. Spence S, Greene MK, Fay F, et al. Targeting Siglecs with a sialic acid-decorated nanoparticle abrogates inflammation. Sci Transl Med. 2015;7(303):303ra140. doi:10.1126/scitranslmed.aab3459

68. Oh B, Lee M. Combined delivery of HMGB-1 box A peptide and S1PLyase siRNA in animal models of acute lung injury. J Control Release. 2014;175:25-35. doi:10.1016/j.jconrel.2013.12.008

69. Piao C, Zhuang C, Choi M, Ha J, Lee M. A RAGE-antagonist peptide potentiates polymeric micelle-mediated intracellular delivery of plasmid DNA for acute lung injury gene therapy. Nanoscale. 2020;12(25):13606-13617. doi:10.1039/D0NR01367F

70. Kim G, Piao C, Oh J, Lee M. Combined delivery of curcumin and the heme oxygenase-1 gene using cholesterol-conjugated polyamidoamine for anti-inflammatory therapy in acute lung injury. Phytomedicine. 2019;56:165-174. doi:10.1016/j.phymed. 2018.09.240
71. Kim G, Piao C, Oh J, Lee M. Self-assembled polymeric micelles for combined delivery of anti-inflammatory gene and drug to the lungs by inhalation. Nanoscale. 2018;10(18):8503-8514. doi:10.1039/C8NR00427G

72. Piao C, Park JH, Lee M. Anti-inflammatory therapeutic effect of adiponectin gene delivery using a polymeric carrier in an acute lung injury model. Pharm Res. 2017;34(7):1517-1526. doi:10.1007/s11095-017-2175-6

73. Bohr A, Tsapis N, Andreana I, et al. Anti-Inflammatory Effect of Anti-TNF-alpha SiRNA Cationic Phosphorus Dendrimer Nanocomplexes Administered Intranasally in a Murine Acute Lung Injury Model. Biomacromolecules. 2017;18(8):2379-2388. doi:10.1021/acs.biomac.7b00572

74. Silva PL, Rocco PRM. Pathophysiology of Acute Respiratory Distress Syndrome. In: Chiumello D, editor. Acute Respiratory Distress Syndrome. Cham: Springer International Publishing; 2017:15-27.

75. Aggarwal NR, King LS, D'Alessio FR. Diverse macrophage populations mediate acute lung inflammation and resolution. $\mathrm{Am}$ J Physiol Lung Cell Mol Physiol. 2014;306(8):L709-L725. doi:10.1152/ajplung.00341.2013

76. Sica A, Mantovani A. Macrophage plasticity and polarization: in vivo veritas. $J$ Clin Invest. 2012;122(3):787-795. doi:10.1172/JCI59643

77. Huang X, Xiu H, Zhang S, Zhang G. The Role of Macrophages in the Pathogenesis of ALI/ARDS. Mediators Inflamm. 2018;2018:1264913. doi:10.1155/2018/1264913

78. Koay MA, Gao X, Washington MK, et al. Macrophages are necessary for maximal nuclear factor-kappa B activation in response to endotoxin. Am J Respir Cell Mol Biol. 2002;26 (5):572-578. doi:10.1165/ajrcmb.26.5.4748

79. Ma Q, Fan Q, Xu J, et al. Calming Cytokine Storm in Pneumonia by Targeted Delivery of TPCA-1 Using Platelet-Derived Extracellular Vesicles. Matter. 2020;3(1):287-301. doi:10.1016/j. matt.2020.05.017

80. Wilhelmsen K, Mesa KR, Prakash A, Xu F, Hellman J. Activation of endothelial TLR2 by bacterial lipoprotein upregulates proteins specific for the neutrophil response. Innate Immun. 2012;18 (4):602-616. doi:10.1177/1753425911429336

81. Potey PM, Rossi AG, Lucas CD, Dorward DA. Neutrophils in the initiation and resolution of acute pulmonary inflammation: understanding biological function and therapeutic potential. J Pathol. 2019;247(5):672-685. doi:10.1002/path.5221

82. Fox ED, Heffernan DS, Cioffi WG, Reichner JS. Neutrophils from critically ill septic patients mediate profound loss of endothelial barrier integrity. Critical Care. 2013;17(5):R226. doi:10.1186/cc13049

83. Lucas R, Verin AD, Black SM, Catravas JD. Regulators of endothelial and epithelial barrier integrity and function in acute lung injury. Biochem Pharmacol. 2009;77(12):1763-1772. doi:10.1016/j.bcp.2009.01.014

84. Jiang J, Huang K, Xu S, Garcia JGN, Wang C, Cai H. Targeting NOX4 alleviates sepsis-induced acute lung injury via attenuation of redox-sensitive activation of CaMKII/ERK1/2/MLCK and endothelial cell barrier dysfunction. Redox Biol. 2020;36:101638. doi:10.1016/j.redox.2020.101638

85. Short KR, Kasper J, van der Aa $\mathrm{S}$, et al. Influenza virus damages the alveolar barrier by disrupting epithelial cell tight junctions. Eur Respir J. 2016;47(3):954-966. doi:10.1183/13993003.01282-2015

86. Wiener-Kronish JP, Albertine KH, Matthay MA. Differential responses of the endothelial and epithelial barriers of the lung in sheep to Escherichia coli endotoxin. J Clin Invest. 1991;88 (3):864-875. doi:10.1172/JCI115388 
87. McClintock D, Zhuo H, Wickersham N, Matthay MA, Ware LB. Biomarkers of inflammation, coagulation and fibrinolysis predict mortality in acute lung injury. Crit Care. 2008;12(2):R41. doi: $10.1186 / \operatorname{cc} 6846$

88. Greineder CF, Brenza JB, Carnemolla R, et al. Dual targeting of therapeutics to endothelial cells: collaborative enhancement of delivery and effect. FASEB j. 2015;29(8):3483-3492. doi:10.1096/fj.15-271213

89. Schmiedl A, Ochs M, Mühlfeld C, Johnen G, Brasch F. Distribution of surfactant proteins in type II pneumocytes of newborn, 14-day old, and adult rats: an immunoelectron microscopic and stereological study. Histochem Cell Biol. 2005;124 (6):465-476. doi:10.1007/s00418-005-0066-0

90. Leibrock LB, Jungnickel H, Tentschert J, et al. Parametric optimization of an air-liquid interface system for flow-through inhalation exposure to nanoparticles: assessing dosimetry and intracellular uptake of $\mathrm{CeO} 2$ Nanoparticles. Nanomaterials. 2020;10:12. doi:10.3390/nano10122369

91. Lin X, Dean DA. Gene therapy for ALI/ARDS. Crit Care Clin. 2011;27(3):705-718. doi:10.1016/j.ccc.2011.04.002

92. Lai SK, Wang YY, Hanes J. Mucus-penetrating nanoparticles for drug and gene delivery to mucosal tissues. Adv Drug Deliv Rev. 2009;61(2):158-171.

93. Al-Jamal WT, Kostarelos K. Liposomes: from a clinically established drug delivery system to a nanoparticle platform for theranostic nanomedicine. Acc Chem Res. 2011;44(10):1094-1104. doi:10.1021/ar200105p

94. Yousefi M, Ehsani A, Jafari SM. Lipid-based nano delivery of antimicrobials to control food-borne bacteria. Adv Colloid Interface Sci. 2019;270:263-277.

95. Suzuki O, Goto T, Yoshino T, Nakamura S, Maeda H. The role of phosphodiesterase 4B in IL-8/LTB4-induced human neutrophil chemotaxis evaluated with a phosphodiesterase 4B inhibitor. Acta Pharm. 2015;65(2):191-197.

96. Kaplan MJ, Radic M. Neutrophil extracellular traps: double-edged swords of innate immunity. J Immunol. 2012;189(6):2689-2695.

97. Papayannopoulos V, Metzler KD, Hakkim A, Zychlinsky A. Neutrophil elastase and myeloperoxidase regulate the formation of neutrophil extracellular traps. J Cell Biol. 2010;191 (3):677-691.

98. Kardara M, Hatziantoniou S, Sfika A, et al. Caveolar uptake and endothelial-protective effects of nanostructured lipid carriers in acid aspiration murine acute lung injury. Pharm Res. 2013;30 (7):1836-1847.

99. Han J, Zern BJ, Shuvaev VV, Davies PF, Muro S, Muzykantov V. Acute and chronic shear stress differently regulate endothelial internalization of nanocarriers targeted to platelet-endothelial cell adhesion molecule-1. ACS Nano. 2012;6(10):8824-8836.

100. Singh AV, Hosseinidoust Z, Park BW, Yasa O, Sitti M. Microemulsion-Based Soft Bacteria-Driven Microswimmers for Active Cargo Delivery. ACS Nano. 2017;11(10):9759-9769. doi:10.1021/acsnano.7b02082

101. Wang AZ, Langer R, Farokhzad OC. Nanoparticle delivery of cancer drugs. Annu Rev Med. 2012;63(1):185-198. doi:10.1146/ annurev-med-040210-162544

102. Hettiarachchi SD, Zhou Y, Seven E, et al. Nanoparticle-mediated approaches for Alzheimer's disease pathogenesis, diagnosis, and therapeutics. J Control Release. 2019;314:125-140. doi:10.1016/ j.jconrel.2019.10.034

103. Li X, Jiang X. Microfluidics for producing poly (lactic-coglycolic acid)-based pharmaceutical nanoparticles. Adv Drug Deliv Rev. 2018;128:101-114. doi:10.1016/j.addr.2017.12.015

104. Lang JD, McArdle PJ, O'Reilly PJ, Matalon S. Oxidantantioxidant balance in acute lung injury. Chest. 2002;122(6 Suppl):314S-320S. doi:10.1378/chest.122.6_suppl.314S
105. Mutlu GM, Factor P. Alveolar epithelial beta2-adrenergic receptors. Am J Respir Cell Mol Biol. 2008;38(2):127-134. doi:10.1165/rcmb.2007-0198TR

106. Chen G, Wang K, Wu P, et al. Development of fluorinated polyplex nanoemulsions for improved small interfering RNA delivery and cancer therapy. Nano Res. 2018;11(7):3746-3761. doi:10.1007/s12274-017-1946-Z

107. Ouchi N, Walsh K. Adiponectin as an anti-inflammatory factor. Clin Chim Acta. 2007;380(1-2):24-30. doi:10.1016/j.cca.2007.01.026

108. Dzmitruk V, Szulc A, Shcharbin D, et al. Anticancer siRNA cocktails as a novel tool to treat cancer cells. Part (B). Efficiency of pharmacological action. Int J Pharm. 2015;485 (1-2):288-294. doi:10.1016/j.ijpharm.2015.03.034

109. Fruchon S, Mouriot S, Thiollier T, et al. Repeated intravenous injections in non-human primates demonstrate preclinical safety of an anti-inflammatory phosphorus-based dendrimer. Nanotoxicology. 2015;9(4):433-441. doi:10.3109/17435390.2014.940406

110. Zhang S. Fabrication of novel biomaterials through molecular self-assembly. Nat Biotechnol. 2003;21(10):1171-1178. doi:10.1038/nbt874

111. Vikram Singh A, Laux P, Luch A, Balkrishnan S, Prasad Dakua S. Bottom-UP assembly of nanorobots: extending synthetic biology to complex material design. Front Nanosci Nanotechn. 2019;5(1):1. doi:10.15761/FNN.1000S2005

112. Singh AV, Ansari MHD, Laux P, Luch A. Micro-nanorobots: important considerations when developing novel drug delivery platforms. Expert Opin Drug Deliv. 2019;16(11):1259-1275. doi:10.1080/17425247.2019.1676228

113. Singh AV, Jahnke T, Kishore V, et al. Cancer cells biomineralize ionic gold into nanoparticles-microplates via secreting defense proteins with specific gold-binding peptides. Acta Biomater. 2018;71:61-71. doi:10.1016/j.actbio.2018.02.022

114. Singh AV, Alapan Y, Jahnke T, et al. Seed-mediated synthesis of plasmonic gold nanoribbons using cancer cells for hyperthermia applications. $J$ Mater Chem B. 2018;6(46):7573-7581. doi:10.1039/C8TB02239A

115. Singh AV, Jahnke T, Xiao Y, et al. Peptide-Induced Biomineralization of Tin Oxide $(\mathrm{SnO}(2))$ Nanoparticles for Antibacterial Applications. J Nanosci Nanotechnol. 2019;19 (9):5674-5686. doi:10.1166/jnn.2019.16645

116. Singh V, Kashyap S, Yadav U, et al. Nitrogen doped carbon quantum dots demonstrate no toxicity under in vitro conditions in a cervical cell line and in vivo in Swiss albino mice. Toxicol Res. 2019;8(3):395-406. doi:10.1039/C8TX00260F

117. Singh AV, Jungnickel H, Leibrock L, et al. ToF-SIMS 3D imaging unveils important insights on the cellular microenvironment during biomineralization of gold nanostructures. Sci Rep. 2020;10 (1):261. doi:10.1038/s41598-019-57136-w

118. Singh AV, Batuwangala $M$, Mundra R, et al. Biomineralized anisotropic gold microplate-macrophage interactions reveal frustrated phagocytosis-like phenomenon: a novel paclitaxel drug delivery vehicle. ACS Appl Mater Interfaces. 2014;6 (16):14679-14689. doi:10.1021/am504051b

119. Singh V, Kumar V, Kashyap S, et al. Graphene Oxide Synergistically Enhances Antibiotic Efficacy in Vancomycin-ResistantStaphylococcus aureus. ACS Applied Bio Mater. 2019;2(3):1148-1157. doi:10.1021/acsabm.8b00757

120. Yang H, Kozicky L, Saferali A, et al. Endosomal pH modulation by peptide-gold nanoparticle hybrids enables potent anti-inflammatory activity in phagocytic immune cells. Biomaterials. 2016;111:90-102. doi:10.1016/j.biomaterials.2016.09.032

121. Muro S, Dziubla T, Qiu W, et al. Endothelial targeting of high-affinity multivalent polymer nanocarriers directed to intercellular adhesion molecule 1. J Pharmacol Exp Ther. 2006;317 (3):1161-1169. doi:10.1124/jpet.105.098970 
122. Salvati A, Pitek AS, Monopoli MP, et al. Transferrinfunctionalized nanoparticles lose their targeting capabilities when a biomolecule corona adsorbs on the surface. Nat Nanotechnol. 2013;8(2):137-143. doi:10.1038/nnano.2012.237

123. Kolaczkowska E, Kubes P. Neutrophil recruitment and function in health and inflammation. Nat Rev Immunol. 2013;13(3):159-175. doi:10.1038/nri3399

124. Klempner MS, Mikkelsen RB, Corfman DH, André-Schwartz J. Neutrophil plasma membranes. I. High-yield purification of human neutrophil plasma membrane vesicles by nitrogen cavitation and differential centrifugation. J Cell Biol. 1980;86(1):21-28. doi:10.1083/jcb.86.1.21

125. Singh AV, Rosenkranz D, Ansari MHD, et al. Artificial intelligence and machine learning empower advanced biomedical material design to toxicity prediction. Adv Intelligent Sys. 2020;2:12. doi:10.1002/aisy.202070125

126. Singh AV, Ansari MHD, Rosenkranz D, et al. Artificial Intelligence and Machine Learning in Computational Nanotoxicology: unlocking and Empowering Nanomedicine. Adv Healthc Mater. 2020;9(17):e1901862. doi:10.1002/ adhm.201901862

127. Singh AV, Jahnke T, Wang S, et al. Anisotropic gold nanostructures: optimization via in silico modeling for hyperthermia. ACS Applied Nano Materials. 2018;1(11):6205-6216. doi:10.1021/ acsanm. $8 \mathrm{~b} 01406$

128. Singh AV, Maharjan RS, Kanase A, et al. Machine-learning-based approach to decode the influence of nanomaterial properties on their interaction with cells. ACS Appl Mater Interfaces. 2021;13 (1):1943-1955. doi:10.1021/acsami.0c18470

129. Bae YH, Park K. Targeted drug delivery to tumors: myths, reality and possibility. J Control Release. 2011;153(3):198-205. doi:10.1016/j.jconrel.2011.06.001

130. Singh AV, Kishore V, Santomauro G, Yasa O, Bill J, Sitti M. Mechanical coupling of puller and pusher active microswimmers influences motility. Langmuir. 2020;36(19):5435-5443. doi:10.1021/acs.langmuir.9b03665

131. Singh AV, Sitti M. Patterned and specific attachment of bacteria on biohybrid bacteria-driven microswimmers. Adv Healthc Mater. 2016;5(18):2325-2331. doi:10.1002/adhm.201600155

132. Singh AV, Ansari MHD, Mahajan M, et al. Sperm Cell Driven Microrobots-Emerging Opportunities and Challenges for Biologically Inspired Robotic Design. Micromachines. 2020;11:4. doi:10.3390/mi11040448

133. Singh AV, Sitti M. Targeted drug delivery and imaging using mobile milli/microrobots: a promising future towards theranostic pharmaceutical design. Curr Pharm Des. 2016;22 (11):1418-1428. doi:10.2174/1381612822666151210124326

134. Morigi V, Tocchio A, Bellavite Pellegrini C, Sakamoto JH, Arnone M, Tasciotti E. Nanotechnology in medicine: from inception to market domination. J Drug Deliv. 2012;2012:389485. doi: $10.1155 / 2012 / 389485$
135. Ali ES, Sharker SM, Islam MT, et al. Targeting cancer cells with nanotherapeutics and nanodiagnostics: current status and future perspectives. Semin Cancer Biol. 2020. doi:10.1016/j. semcancer.2020.01.011

136. Rhen T, Cidlowski JA. Antiinflammatory action of glucocorticoids-new mechanisms for old drugs. $N$ Engl J Med. 2005;353 (16):1711-1723. doi:10.1056/NEJMra050541

137. Barreto RSS, Quintans JSS, Amarante RKL, et al. Evidence for the involvement of TNF-alpha and IL-1beta in the antinociceptive and anti-inflammatory activity of Stachys lavandulifolia Vahl. (Lamiaceae) essential oil and (-)-alpha-bisabolol, its main compound, in mice. J Ethnopharmacol. 2016;191:9-18. doi:10.1016/ j.jep.2016.06.022

138. Baker K, Marcus CB, Huffman K, Kruk H, Malfroy B, Doctrow SR. Synthetic combined superoxide dismutase/catalase mimetics are protective as a delayed treatment in a rat stroke model: a key role for reactive oxygen species in ischemic brain injury. J Pharmacol Exp Ther. 1998;284(1):215-221.

139. Gonçalves-de-albuquerque CF, Medeiros-de-moraes IM, Oliveira FM, et al. Omega-9 oleic acid induces fatty acid oxidation and decreases organ dysfunction and mortality in experimental sepsis. PLoS One. 2016;11(4):e0153607. doi:10.1371/journal. pone. 0153607

140. Birrell MA, Hardaker E, Wong S, et al. Ikappa-B kinase-2 inhibitor blocks inflammation in human airway smooth muscle and a rat model of asthma. Am J Respir Crit Care Med. 2005;172 (8):962-971. doi:10.1164/rccm.200412-1647OC

141. Silva PL, Pelosi P, Rocco PRM. Personalized pharmacological therapy for ARDS: a light at the end of the tunnel. Expert Opin Investig Drugs. 2020;29(1):49-61. doi:10.1080/13543784.2020.1699531

142. Aikawa N, Kawasaki Y. Clinical utility of the neutrophil elastase inhibitor sivelestat for the treatment of acute respiratory distress syndrome. Ther Clin Risk Manag. 2014;10:621-629. doi:10.2147/ TCRM.S65066

143. Banik K, Ranaware AM, Harsha C, et al. Piceatannol: a natural stilbene for the prevention and treatment of cancer. Pharmacol Res. 2020;153:104635. doi:10.1016/j.phrs.2020.104635

144. Brandvold KR, Steffey ME, Fox CC, Soellner MB. Development of a highly selective c-Src Kinase Inhibitor. ACS Chem Biol. 2012;7(8):1393-1398. doi:10.1021/cb300172e

145. Vincent F, Duncton MA. TRPV4 agonists and antagonists. Curr Top Med Chem. 2011;11(17):2216-2226. doi:10.2174/ 156802611796904861
International Journal of Nanomedicine

\section{Publish your work in this journal}

The International Journal of Nanomedicine is an international, peerreviewed journal focusing on the application of nanotechnology in diagnostics, therapeutics, and drug delivery systems throughout the biomedical field. This journal is indexed on PubMed Central, MedLine, CAS, SciSearch ${ }^{\mathbb{R}}$, Current Contents ${ }^{\mathbb{B}} /$ Clinical Medicine,
Journal Citation Reports/Science Edition, EMBase, Scopus and the Elsevier Bibliographic databases. The manuscript management system is completely online and includes a very quick and fair peer-review system, which is all easy to use. Visit http://www.dovepress.com/ testimonials.php to read real quotes from published authors. 